\title{
Gulf Stream Separation in Numerical Ocean Models
}

\author{
Eric P. Chassignet \\ Center for Ocean-Atmospheric Prediction Studies, Florida State University, Tallahassee, Florida, USA
}

David P. Marshall

Atmospheric, Oceanic and Planetary Physics, University of Oxford, Oxford, UK

\begin{abstract}
This chapter summarizes our present knowledge of Gulf Stream separation in numerical ocean models. High horizontal resolution ocean numerical models are now capable of simulating quite realistically the separation and path of the Gulf Stream, and significant advances have been made in the last decade in our understanding of western boundary current separation. However, the Gulf Stream separation in numerical models continues to be a challenge because it remains very sensitive to the choices made for subgrid scale parameterizations.
\end{abstract}

\section{INTRODUCTION}

An accurate depiction of currents and associated features, such as mesoscale eddies, fronts, and jets, is essential to any eddy-resolving ocean model when modeling the global ocean circulation. Western boundary currents are an integral part of the wind-driven circulation, and the most conspicuous ones, such as the Gulf Stream and Kuroshio, carry large amounts of warm water from the tropics toward the northern latitudes. After separation, the western boundary currents are subject to intense air-sea interactions that translate into large heat loss (Plate 1).

One of the largest biases in current global climate models is the misrepresentation of the fluxes at the air-sea interface. This is caused by the large sea surface temperature errors (and therefore heat fluxes) that result from western boundary currents that usually overshoot the observed separation latitude [Kiehl and Gent, 2004]. The horizontal grid spacing used in the ocean component of these global climate models is quite coarse (on the order of $1^{\circ}$ ) when compared to stateof-the-art ocean-only global models (on the order of $1 / 10^{\circ}$ ).

Ocean Modeling in an Eddying Regime

Geophysical Monograph Series 177

Copyright 2008 by the American Geophysical Union. 10.1029/177GM05
There is a considerable improvement in the numerical representation of western boundary current separation when the horizontal grid spacing is approximately $10 \mathrm{~km}$ or less. As stated by Bryan et al. [2007], it has often been argued that this regime shift may result from the fact that the first baroclinic Rossby radius of deformation is actually resolved throughout most of the domain, thereby providing a good representation of baroclinic instability processes, but it may also be at this resolution that a critical Reynolds number is exceeded for separation to occur correctly [Dengg, 1993].

Identifying the dynamics responsible for western boundary current separation has been a long-standing challenge. It is fair to say that a proper western boundary current separation in a numerical model is the result of many contributing factors and that the separation mechanism remains very sensitive to choices made in the numerical model for subgrid scale parameterizations. There is yet no single recipe that would guarantee a correct separation of all western boundary currents in a global model. Much of the focus in the literature has been on achieving a proper Gulf Stream separation [e.g., Dengg et al., 1996], but each western boundary current (Gulf Stream, Kuroshio, Brazil/Malvinas, Agulhas, East Australian, etc.) presents its own challenge and will respond differently to the chosen numerical algorithms and forcing functions.

In this chapter, we review our current knowledge of Gulf Stream separation in numerical ocean models. Since the 


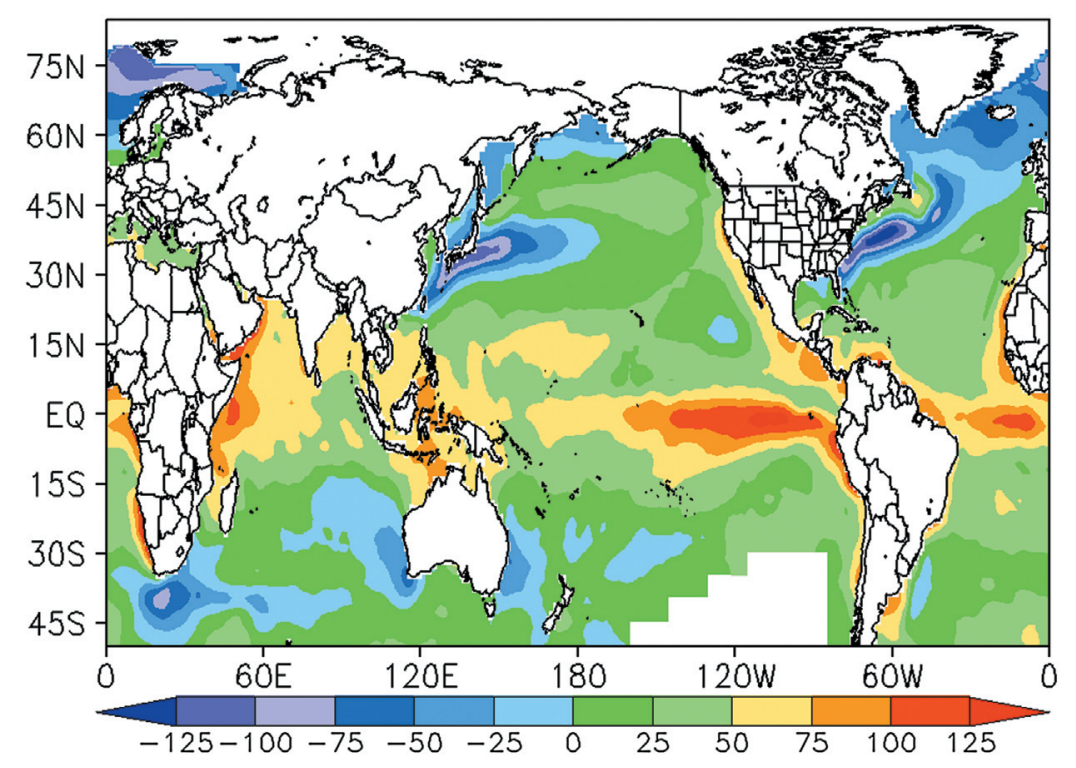

Plate 1. Annual mean ocean to atmosphere surface heat flux from the National Oceanography Centre, Southampton, UK. The units are in $\mathrm{W} / \mathrm{m}^{2}$. Note the ocean heat losses in the western boundary currents (in blue). 
last major review of Gulf Stream separation by Dengg et al. [1996], there have been significant advances in our understanding of the influences of coastline geometry, bottom topography, inertia, and the deep western boundary current (DWBC) on the Gulf Stream separation, and also on the influence of boundary conditions as implemented in numerical ocean models. However, the most significant development has been the advent of the higher-resolution numerical ocean models capable of more realistically simulating the separation and path of the Gulf Stream.

The layout of this chapter is as follows. First, in Section 2, a brief overview of the literature on Gulf Stream separation mechanisms is presented with an extensive list of references. In Section 3, the relevance of several of these mechanisms to eddy-resolving models is discussed. Section 4 focuses on the representation of western boundary currents in stateof-the-art eddy-resolving ocean general circulation models (OGCMs) and the difficulties still faced by numerical modelers despite the improvements that result from the use of eddy-resolving grid spacing. Section 5 provides a brief discussion on the validation of the modeled boundary currents against observations.

\section{PRIMARY PHYSICAL MECHANISMS}

The persistence of unrealistic Gulf Stream separation in numerical models has prompted many theories of possible mechanisms influencing the separation of a western boundary current from the coast. The early linear frictional models [e.g., Stommel, 1948; Munk, 1950] suggest that separation takes place as a result of the change in sign of the wind stress curl. This theory is further supported by the fact that the observed mean path of the Gulf Stream roughly overlies the zero wind stress curl line (ZWCL). The ZWCL, however, shows considerable seasonal variation [e.g., Isemer and Hasse, 1987], while the point of separation shows remarkable consistency. Inclusion of the nonlinear terms and associated boundary conditions (no-slip or free-slip) induces considerable variations in the separation latitude [Blandford, 1971; Moro, 1988; Verron and Le Provost, 1991; Cessi, 1991; Chassignet and Gent, 1991; Haidvogel et al., 1992; Verron and Blayo, 1996; Adcroft and Marshall, 1998]. Other mechanisms have been put forth as being important in the separation process, such as potential vorticity crisis [Kamenkovich, 1966; Ierley and Ruehr, 1986; Ierley, 1987, Cessi et al., 1987; Ierley and Young, 1988; Cessi, 1990; Kiss, 2002], a region of adverse pressure gradient [Haidvogel et al., 1992; Baines and Hugues, 1996; Marshall and Tansley, 2001; Kiss, 2002], collision with another western boundary current [Cessi, 1991; Agra and Nof, 1993], outcropping of isopycnals [Parsons, 1969; Kamenkovich and
Reznik, 1972; Veronis, 1973; Moore and Niiler, 1974; Anderson and Moore, 1979; Ou and de Ruijter, 1986; Huang, 1987; Huang and Flierl, 1987; Gangopadhyay et al., 1992; Chassignet and Bleck, 1993; Chassignet, 1995], interaction with the DWBC [Thompson and Schmitz, 1989; Spall, 1996a, 1996b; Tansley and Marshall, 2000], surface cooling [Veronis, 1976, 1978; Pedlosky, 1987; Nurser and Williams, 1990; Ezer and Mellor, 1992; Chassignet et al., 1995], and multiple equilibria [Jiang et al., 1995; Nauw et al., 2004]. Most of the cited studies, however, do not include any coastline geometry or bottom topography. Separation can be influenced by a change in coastline orientation or by a change in bottom topography [Warren, 1963, Greenspan, 1963; Pedlosky, 1965; Kamenkovich and Reznik, 1972; Smith and Fandry, 1976; Stern and Whitehead, 1990; Spitz and Nof, 1991; Salmon, 1992; Dengg, 1993; Salmon, 1994; Thompson, 1995; Myers et al., 1996; Özgökmen et al., 1997; Stern, 1998; Tansley and Marshall, 2000, 2001; Munday and Marshall, 2005]. Eddy-topography interactions have also been surmised to play a role in the separation process [Holloway, 1992; Cherniawsky and Holloway, 1993; Eby and Holloway, 1994; Hurlburt et al., 2008; Hulburt and Hogan, 2008].

\section{PROCESS STUDY EXPERIMENTS}

In this section, we review several process study experiments that are particularly relevant to the discussion of Gulf Stream separation in realistic eddy-resolving ocean models.

\subsection{Wind Forcing Boundary Condition}

In the ocean, the wind stress acts over the surface Ekman layer, and the wind momentum is distributed within the surface mixed layer. Thus, the depth over which the wind forcing is felt by the ocean is space- and time-dependent. Figure 1 illustrates the sensitivity of the separation latitude to the depth over which the momentum of the wind is distributed by displaying the time average upper nondivergent streamfunction of four eddy-resolving adiabatic numerical models configured in a rectangular ocean basin and driven by a meridionally symmetric zonal wind stress.

The approximations made to obtain the quasi-geostrophic equations imply a symmetric response (Figure 1a) when a symmetric forcing is specified. As soon as the latter is relaxed, the midlatitude jet exhibits asymmetries [Verron and Le Provost, 1991]. The main difference between the isopycnic- and depth-coordinate models (separation south and north of the ZWCL, respectively; Figures 1c and d) results from the way the wind forcing is applied as a body force over the upper layer or at the first level. In the isopycnic coordinate model, the upper layer interface is shallower in the subpolar 
(a)

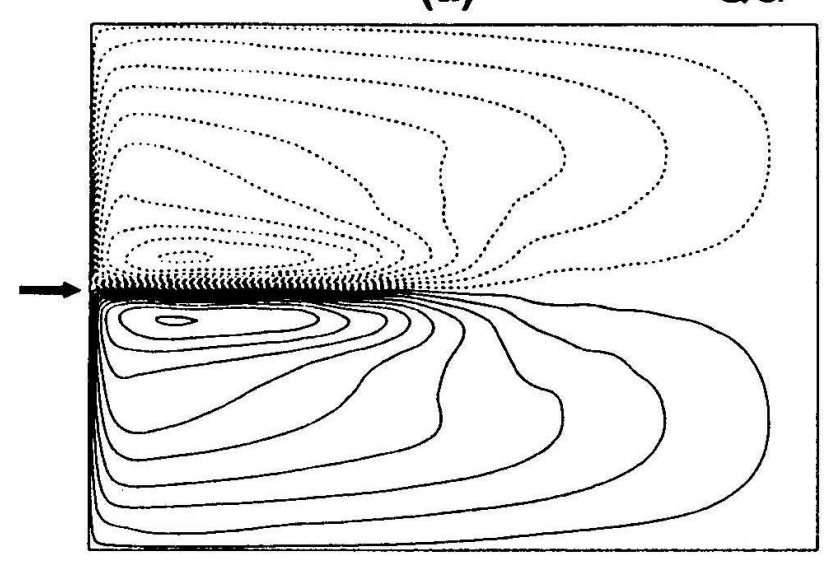

(b)

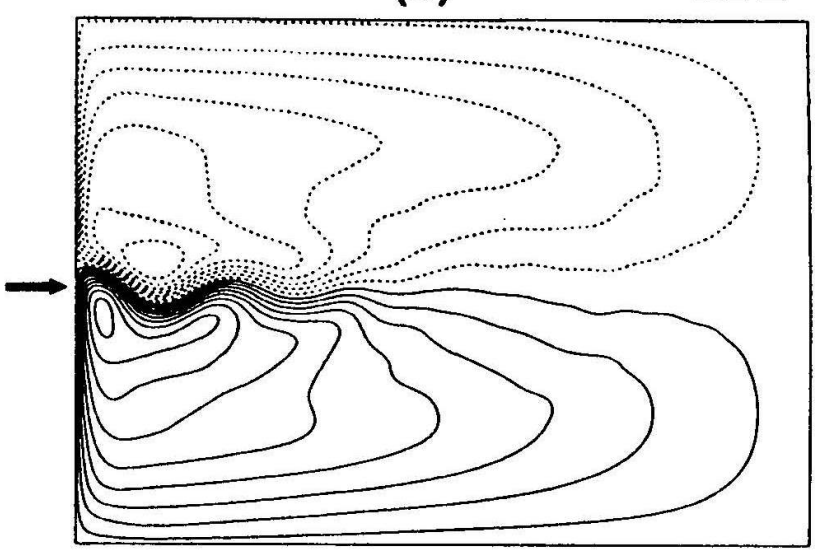

(c)

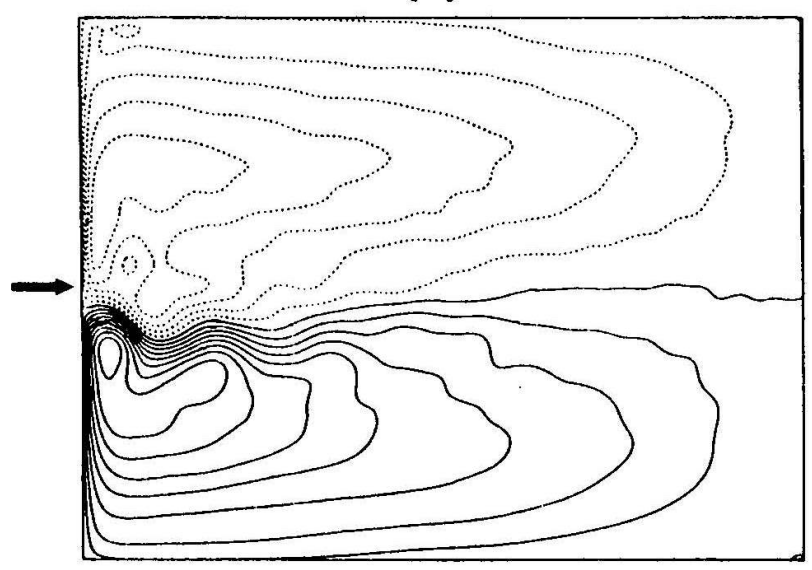

(d)

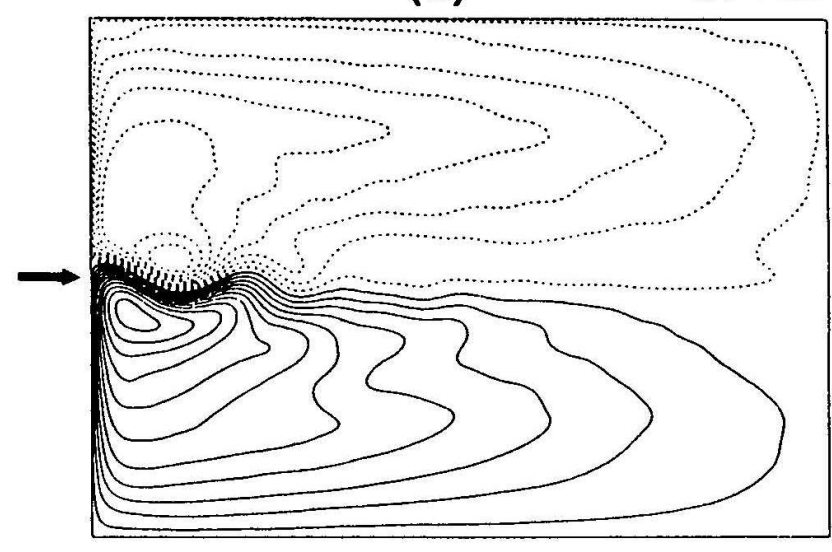

Figure 1. Time average of the upper non-divergent streamfunction for four numerical models: (a) quasi-geostrophic equations, (b) linear balance equations, (c) primitive equations with isopycnic coordinates, and (d) primitive equations with depth coordinates. The arrow points to the zero wind stress curl line (ZWCL). For more details, the reader is referred to Chassignet and Gent [1991].

gyre and deeper in the subtropical gyre [Huang, 1987]. This leads to stronger flows in the subpolar gyre, weaker flows in the subtropical gyre, and therefore the tendency for northward separation due to the Coriolis force (clearly visible in Figures $1 \mathrm{~b}$ and $\mathrm{d}$ for the linear balance equations and depthcoordinate simulations) is then overcome by the tendency for a southward separation (Figure 1c) caused by a stronger subpolar gyre circulation.

Depth variations in the upper layer interface of the isopycnic coordinate model can, in some cases, be large enough for outcropping to occur and move the separation latitude further south [Parsons, 1969; Veronis, 1973; Huang, 1987;
Chassignet and Bleck, 1993]. In the absence of thermodynamics, the amount of fluid in the upper layer is fixed, and this amount, together with the strength of the wind stress, dictates the outcrop location and size. In reality, the mixed layer depth over which the wind stress transfers momentum is deeper in the subpolar gyre than in the subtropical gyre, and a purely adiabatic model cannot capture this distribution. Furthermore, as discussed by Pedlosky [1987], Nurser and Williams [1990], and Chassignet et al. [1995], the presence of diabatic cross-isopycnal flows at the outcrop affects the nature of the solution, and the separation is not required anymore to be south of the ZWCL. In summary, as stated by 
Veronis [1978], the intensity of the thermal driving, as well as the wind stress, has to be taken into account in determining the separation latitude of western boundary currents.

\subsection{Lateral Boundary Condition}

The choice of lateral boundary condition in a numerical model has a profound influence on the boundary current separation in a rectangular ocean basin [Haidvogel et al., 1992; Verron and Blayo, 1996]. As stated by Adcroft and Marshall [1998], while the appropriate boundary condition for a continuum fluid is no-slip (zero velocity on the boundary), it is less clear that no-slip is appropriate for a finite-resolution ocean model in which the boundary current is barely resolved by the numerical grid. Alternative slippery boundary conditions have been proposed: the free-slip condition is the most widespread, in which the tangential shear at the boundary vanishes; hyper-slip and super-slip conditions have also been proposed to enable advection of vorticity along coastlines (see Pedlosky [1996] for a review).

The sensitivity of the separation latitude to lateral boundary conditions where the tangential stress is proportional to the tangential velocity is illustrated in Figure 2 for a quasigeostrophic numerical model configured in a rectangular ocean basin and driven by a zonally symmetric wind stress. The constant of proportionality $(\alpha)$ has limiting values of zero

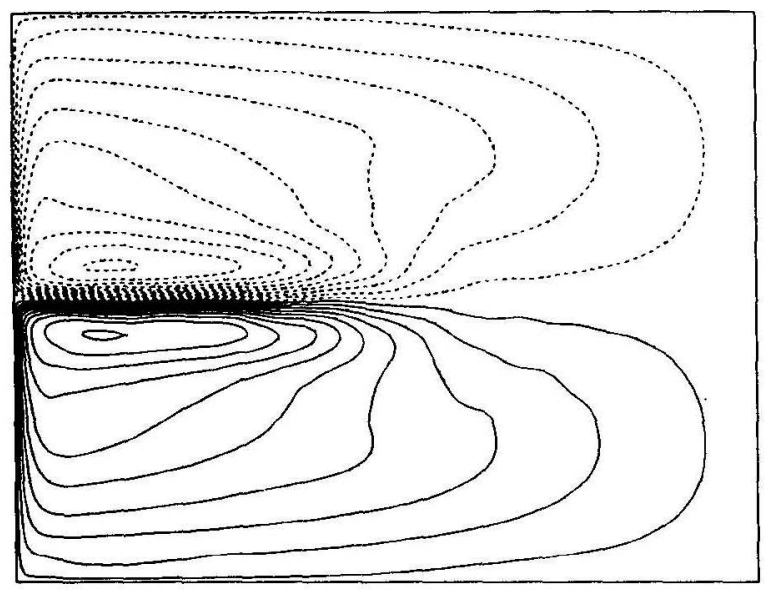

a) $a=0$

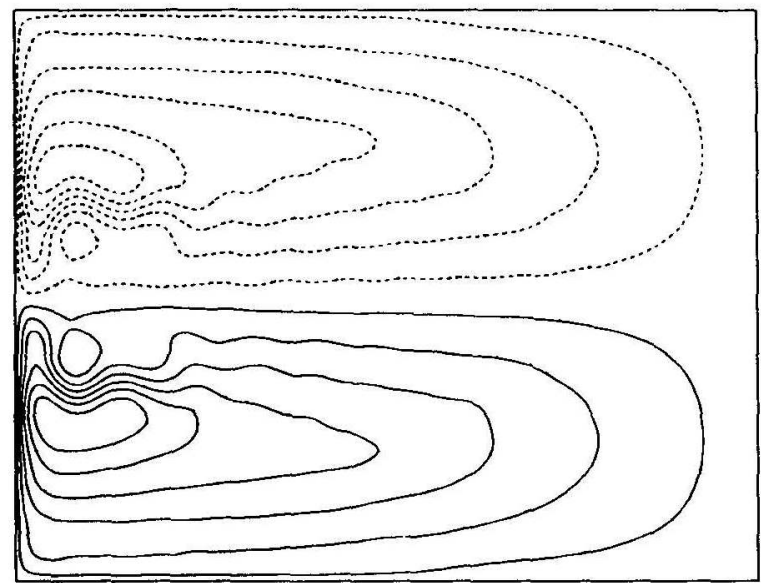

c) $a=6.5$

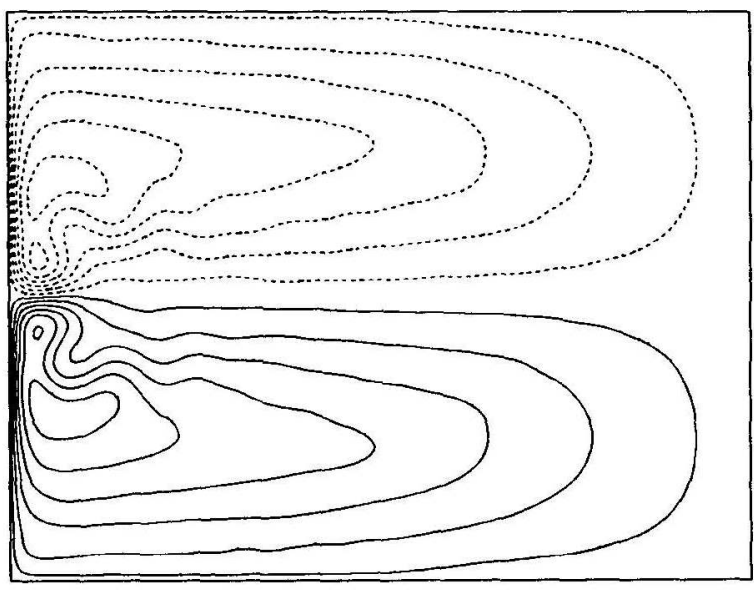

b) $a=5$

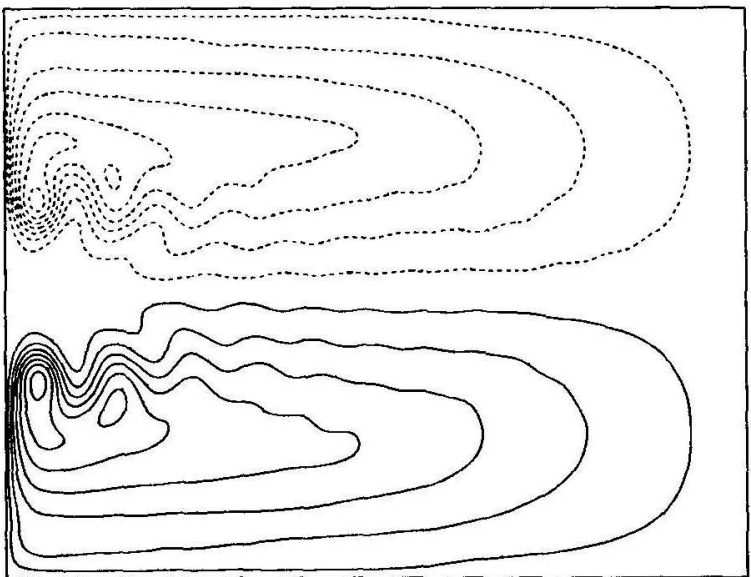

d) $a=100$

Figure 2. Time average of the upper streamfunction with (a) free-slip, (b, c) partial-slip, and (d) no-slip boundary conditions with symmetric wind stress. For more details, the reader is referred to Haidvogel et al. [1992]. 
and infinity, corresponding to free-slip and no-slip conditions, respectively. Significant changes in the time-mean behavior of the solution are observed to occur with increasing $\alpha$. These changes include a gradual retreat of the separation points of the western boundary currents in the subtropical and subpolar gyres. The difference between free-slip and no-slip boundary conditions is further illustrated in Figure 3 for two experiments identical to Figures $2 \mathrm{a}$ and d, except for uniform westerly winds in the northern half of the basin, i.e., zero wind stress curl. The time-mean field for the no-slip experiment (Figure $3 b$ ) is virtually identical in the subtropical gyre when compared to the symmetric wind forcing case (Figure 2d). The separation point in the free-slip case (Figure 3a) does move

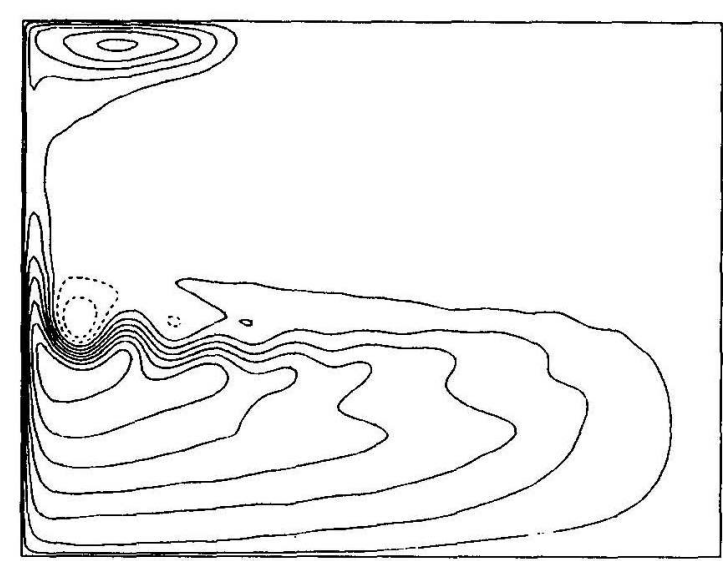

a) $a=0$

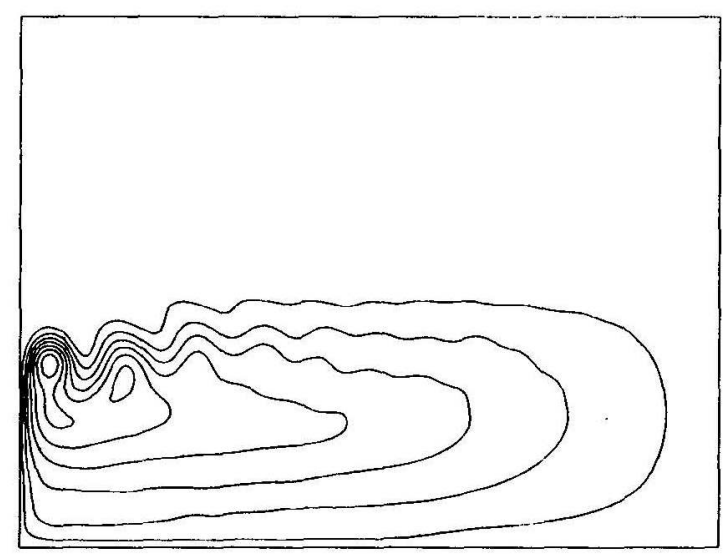

b) $a=100$

Figure 3. Time average of the upper streamfunction with (a) free-slip and (b) no-slip boundary conditions with asymmetric wind stress. For more details, the reader is referred to Haidvogel et al. [1992]. considerably northward in the absence of a colliding northern gyre boundary current. Haidvogel et al. [1992] found the separation to be associated with the occurrence of an adverse value of the higher-order pressure gradient term in the time-mean momentum budget just upstream of the separation point.

The distinction between free-slip and no-slip boundary conditions can become blurred in models when the coastline is irregular and is not oriented north-south as in the above configurations. Coastlines in numerical ocean models are oriented at various finite angles to the model grid and are usually replaced in finite difference models by a piecewiseconstant approximation in which the model coastline is everywhere aligned with the model grid. Adcroft and Marshall [1998] studied the consequences of this piecewise-constant approximation by rotating the numerical grid at various finite angles to the physical coastline. They demonstrated that piecewise-constant coastlines exert a spurious form stress on model boundary currents, which depends on both the implementation of the lateral boundary condition and the form of the viscous stress tensor. This drag can, in some cases, introduce premature boundary current separation.

The no-slip or free-slip boundary conditions are often implemented in ocean numerical models using "ghost points" located half a grid point outside the model domain (Figure 4a). Along a no-slip boundary, the velocity at the ghost point is set equal and opposite to that of the interior value, whereas along a free-slip boundary, the ghost velocity is set equal to the interior value. There is, however, no need for ghost points when the model variables are staggered in the form of an Arakawa C-grid (used by most eddy-resolving models) and the latter is rotated $45^{\circ}$ (Figure $4 \mathrm{~b}$ ). In the latter, the boundary conditions are identical for no-slip and free-slip, which contradicts the use of different boundary conditions. Furthermore, Adcroft and Marshall [1998] showed that the net viscous stress is then underestimated by a factor $\sqrt{2}$ for no-slip and finite (instead of zero) for free-slip.

These spurious form stresses are present even if the boundary layer is resolved by several grid points, but the stresses can be reduced (and, in some cases, eliminated) when the boundary condition is directly applied to the viscous stress tensor in a vorticity-divergence form. Similar results are obtained for alternative finite-difference methods (energy conservation, variables staggered on an Arakawa B-grid, etc.). The impacts of different combinations of advection schemes and stress tensors have been studied further by Dupont et al. [2003].

Adcroft and Marshall [1998] conclude by stating that ocean modelers need to reconsider the traditional treatment of coastlines and that the ultimate goal should be to develop an ocean model in which the circulation is insensitive to the orientation of the numerical grid. Ultimately, unstructured meshes hold significant promise in this respect [Piggott et al., 2008]. 


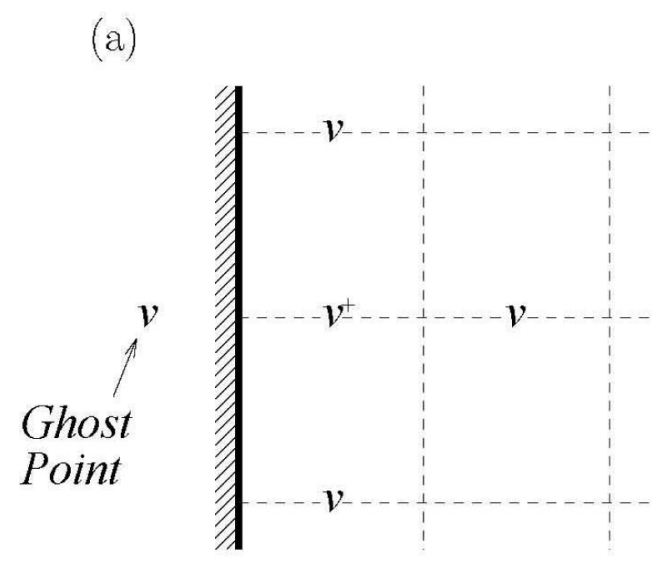

(b)

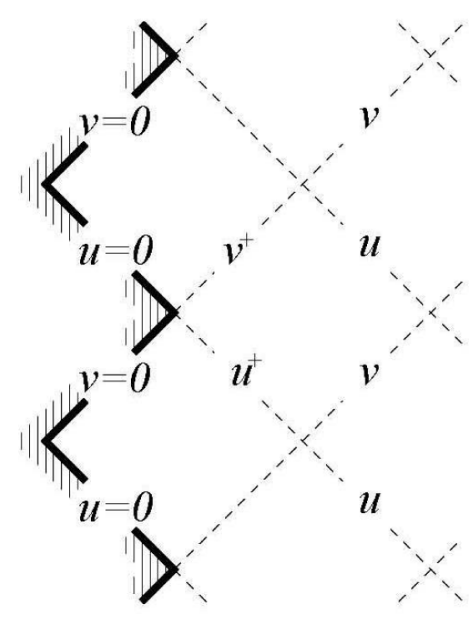

Figure 4. Schematic showing the distribution of velocity points adjacent to a north-south boundary on (a) an unrotated grid and (b) an Arakawa $\mathrm{C}$-grid rotated at $45^{\circ}$. For more details, the reader is referred to Adcroft and Marshall [1998].

\subsection{Coastlines, Bottom Topography, and Inertia}

The importance of coastline orientation and bottom topography on western boundary current separation has been investigated over the years in some detail, especially for the Gulf Stream. In the North Atlantic, the western boundary current, after flowing over the shallow continental shelf (water depths of less than 1,000 m) between the Florida Straits and Cape Hatteras, separates by crossing the continental rise where the bottom topography drops sharply to 5,000 $\mathrm{m}$ within a few hundred kilometers. From a potential vorticity analysis combined with observational considerations, Warren [1963] inferred that the topography of the continental rise was of significant importance in controlling the Gulf Stream's path. In a similar study, Greenspan [1963] also argued that bottom topography exerts a considerable influence on the separation of the Gulf Stream from the coastline and on its subsequent meander pattern. In a barotropic numerical study, Holland [1967] concluded that the separation of the Gulf Stream, meandering, and transport are strongly related to topographic effects. In a later study, Holland [1973] demonstrated that it was essential to include the effect of stratification when investigating the influence of bottom topography, as the bottom torque can be highly modified by the baroclinicity of the flow [see also Myers et al., 1996]. The impact of a continental slope on the dynamics of a western boundary current was also addressed by Salmon [1992, 1994] by integrating analytically and numerically the planetary geostrophic equations for a two-layer, double-gyre system. Salmon [1994] demonstrated that the low transport values produced by the wind in the subpolar gyre were carried southwestward along the $f / h$ lines to produce a region of southward flow between the coast and the western boundary current of the subtropical gyre. However, the planetary geostrophic equations used by Salmon [1992, 1994] do not incorporate the inertial terms, which are of importance in western boundary currents [e.g., Harrison and Holland, 1981]. Thompson [1995] studied the effect of continental rises in the context of a three-layer quasi-geostrophic model. Thompson [1995] considered a symmetrically forced double-gyre circulation with free-slip boundary conditions along the western wall and found that the presence of topography broke the symmetry between the subpolar and subtropical gyres. The mean path of the midlatitude jet was deflected to the north of the ZWCL, while the separation point remained unaffected.

Dengg [1993] demonstrated in a barotropic flat bottom model that the turn of the coastline away from the western boundary current can induce separation, provided that the current is highly inertial and that no-slip boundary conditions are prescribed. The key process was the production of positive relative vorticity along the coast and its subsequent advection to the separation point via nonlinear terms in the vorticity equation. Marshall and Tansley [2001] and Munday and Marshall [2005] have related these results to the generation of flow deceleration and an adverse pressure gradient. They show that the $\beta$ effect acts to accelerate a western boundary current and can suppress its separation. Thus, there is a critical coastline curvature needed to overcome the accelerating influence of the $\beta$ effect in order for separation to occur. Özgökmen et al. [1997] extended the works of Dengg [1993] and Thompson [1995] to baroclinic flows with bottom topography and coastline orientation by exploring the joint effects of (1) wind forcing, (2) bottom 
topography, and (3) inertia on the mid-latitude jet separation in a two-layer quasi-geostrophic model. The sensitivity of the separation latitude to the meridional structure of the wind stress distribution was first investigated in a series of no-slip experiments with a simplified wedge-shaped coastline and with a flat bottom. In all cases, the separation latitude was found to be strongly dependent on the position of the maximum wind stress curl (Figure 5).

Inclusion of an idealized bottom topography consisting of a smooth and gradual rise to represent the continental shelf significantly modified the upper-layer flow pattern by forcing the western boundary current to follow the $f / h$ contours and to overshoot the flat-bottom separation latitude (Figure 6a). The influence of bottom topography can be expressed as the difference between the topographic stretching associated with the barotropic flow and a correction term that represents the joint effect of baroclinicity and bottom relief, the so-called JEBAR term [Sarkisyan and Ivanov, 1971; Mertz and Wright, 1992]. In the absence of direct forcing (i.e., a DWBC or buoyancy forcing), the lower layer can be set in motion only through eddy momentum fluxes generated by instabilities. Topographic stretching is then generated, provided that a mean flow is established in the lower layer by the fluctuations. Feedback to the upper layer will then be es- tablished via vortex stretching. In other words, topographic effects will be felt by the upper layer in high eddy activity regions. Özgökmen et al. [1997] showed that if eddy fluctuations are high at the separation point, then the jet feels the topography strongly and, consequently, is unable to cross the $f / h$ contours. The main factor that was found to minimize the impact of the topographic stress [Holloway, 1992] near the separation point is high inertia. Higher inertia facilitates the separation by decoupling the upper layer from the lower layer when the current crosses the $f / h$ contours. The eddytopography interactions are then minimal over the continental rise and become important only in the meandering jet region (Figure 6b). Contrary to the results of the flat-bottom experiments, once inertial effects dominate, the separation latitude is no longer found to be sensitive to the wind stress distribution. The path of the jet, however, once separated, does depend on the wind stress distribution.

Stern [1998] has also proposed a role for the downstream convergence of the isobaths on boundary current separation; this mechanism may be particularly pertinent for the Gulf Stream, as the continental shelf narrows abruptly at Cape Hatteras. Upstream of this convergence, the topography exerts a stabilizing influence on the boundary current. However, as the isobaths converge, the boundary current is
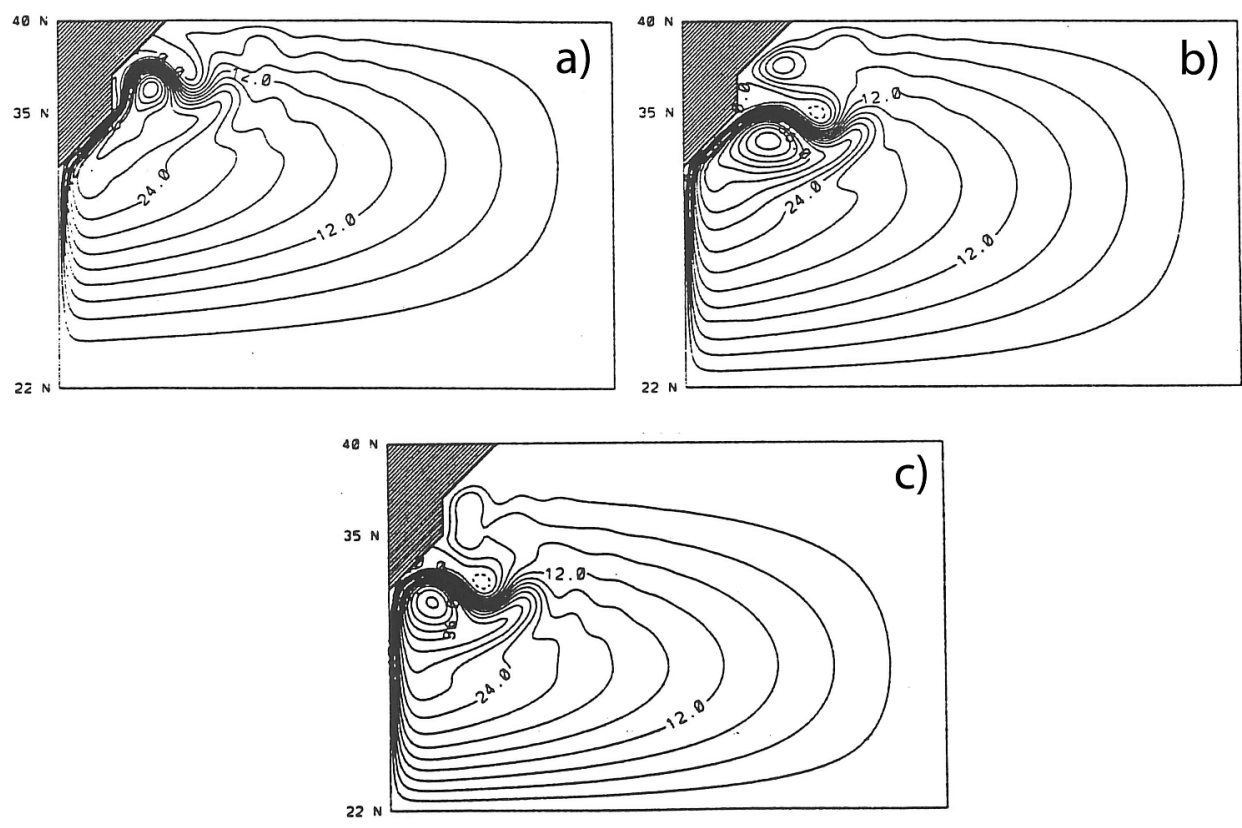

Figure 5. Upper-layer transport streamfunctions $(\mathrm{CI}=3 \mathrm{~Sv})$ for the flat bottom experiments with an anticyclonic zonal wind stress of varying meridional structure: (a) intensified to the north, (b) quasi-symmetric, and (c) intensified to the south. For more details, the reader is referred to Özgökmen et al. [1997]. 

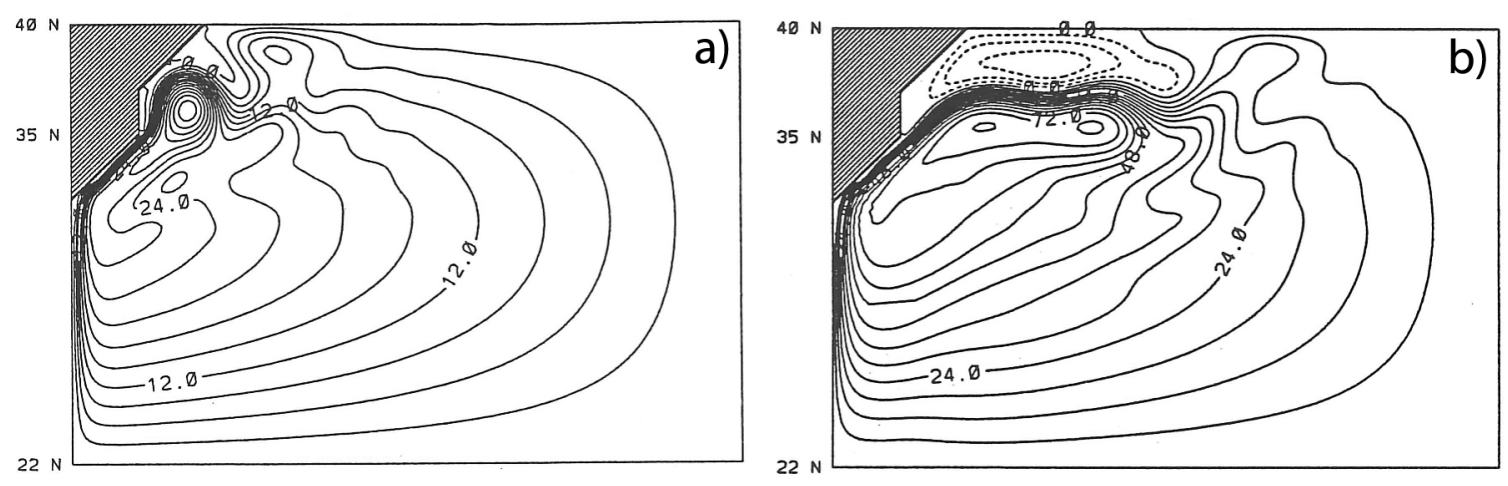

Figure 6. Upper-layer transport streamfunctions for (a) the bottom topography experiment with the same quasi-symmetric anticyclonic zonal wind stress used in the top right panel of Figure $5(\mathrm{CI}=3 \mathrm{~Sv})$ and $(\mathrm{b})$ the same experiment where the amplitude of the Eckman pumping is doubled, thereby increasing the western boundary current inertia $(\mathrm{CI}=6 \mathrm{~Sv})$. For more details, the reader is referred to Özgökmen et al. [1997].

forced into deeper water and therefore able to continue as a free jet, shielded from the topographic influence by the stratification beneath. An important aspect of both the Özgökmen et al. [1997] and Stern [1998] models is that they remind us that in reality, boundary currents such as the Gulf Stream separate from sloping bottom boundaries rather than lateral sidewalls.

Finally, when compared with other western boundary currents, the Gulf Stream separation point is very stable and, in the absence of other credible mechanisms, it seems likely that the geometry of the coastline and/or bottom topography is the major factor responsible for this stability.

\subsection{Deep Western Boundary Current}

A further factor that may influence separation in the case of the Gulf Stream is its interaction with the DWBC. The path of the DWBC is strongly constrained by bottom topography; at Cape Hatteras, where the continental shelf widens abruptly, the DWBC is forced to move offshore and pass beneath the Gulf Stream. The DWBC may influence Gulf Stream separation through two distinct mechanisms: southward "advection" of the separation point [Thompson and Schmitz, 1989] and generation of an adverse pressure gradient within the Gulf Stream through the vortex stretching induced by the descent of the DWBC [Tansley and Marshall, 2000].

The first mechanism can be understood by considering a two-layer model of the Gulf Stream and the DWBC. Assuming the flow is in geostrophic balance to leading order, one can show that the depth of the upper layer, and hence the path of the Gulf Stream, is "advected" by the flow in the lower DWBC layer [Thompson and Schmitz, 1989]. While this mechanism is inherently transient in nature, Tansley and
Marshall [2000] note that the widening of the continental shelf at Cape Hatteras sets a natural limit to the southward advection of the Gulf Stream separation point.

The second mechanism can be understood by considering the vorticity balance of the Gulf Stream. As the DWBC descends beneath the Gulf Stream [Pickart and Smethie, 1993], the resultant vortex stretching generates a cyclonic vorticity anomaly within the Gulf Stream, which can be shown to decelerate the flow and induce an adverse pressure gradient [Tansley and Marshall, 2000].

Idealized numerical experiments (Figure 7) confirm that the DWBC can shift the Gulf Stream separation point southward [e.g., Thompson and Schmitz, 1989]. The extent of this southward shift is increased when both the upper and lower cores of the DWBC are individually resolved due to the increased resolution of the DWBC and the resultant increase in flow speeds [Spall, 1996a]. The upper core of the DWBC becomes entrained into the eddy-driven recirculation gyre to the north of the separated Gulf Stream and mixes with water from the gyre interior before returning to the western boundary via the southern recirculation gyre; in contrast, the lower core of the DWBC flows southward along the western boundary and is relatively unaffected by the crossover.

Low-frequency oscillations are also obtained in many parameter regimes, which Spall [1996b] attributes to the entrainment of the upper core of the DWBC into the separating Gulf Stream in different phases of the oscillation. In one phase, entrainment of the upper core of the DWBC into the eddydriven recirculation gyres modifies the meridional potential vorticity gradient and stabilizes the separated Gulf Stream, in turn reducing the eddy potential vorticity fluxes and weakening the eddy-driven recirculation gyres. In the other phase with weakened recirculation gyres, the absence of entrainment 

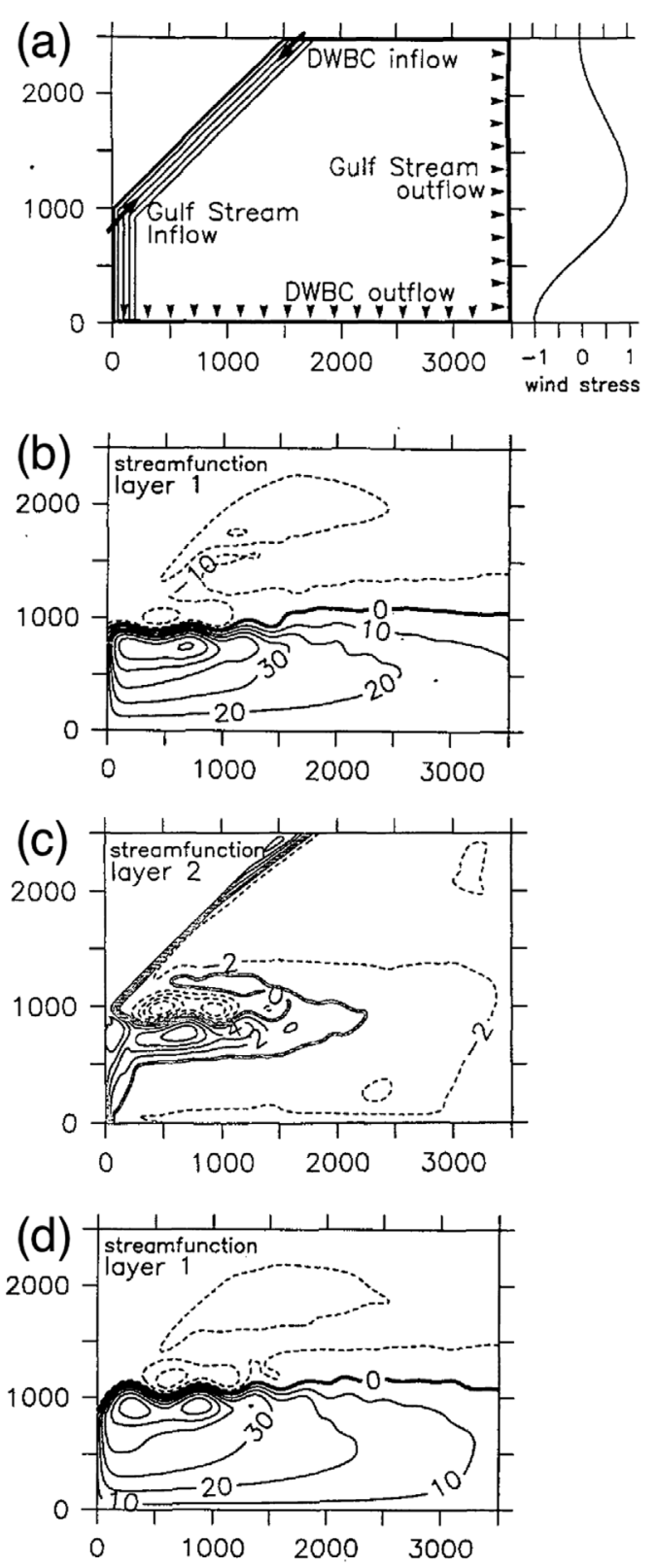

Figure 7. Illustration of the role of the DWBC on Gulf Stream separation in the idealized three-layer model of Spall [1996a]: (a) model configuration; streamfunction for the (b) Gulf Stream layer and (c) upper DWBC layer in the control case; (d) streamfunction for the Gulf Stream layer in the case with no DWBC. For more details, the reader is referred to Spall [1996a].

of the upper core of the DWBC reverses the meridional potential vorticity gradient, destabilizing the separated Gulf Stream and strengthening the recirculation gyres. Katsman et al. [2001] further discuss the stability properties, bifurcation structure, and timescales of these regimes.

\section{REPRESENTATION OF GULF STREAM SEPARATION IN EDDY-RESOLVING OGCMS}

Recent advances in computer architecture now allow for the numerical integration of state-of-the-art basin models with a grid resolution of $1 / 10^{\circ}$ or higher (routinely on basin scale and less so globally). There are only a handful of results that have been published in the literature on simulations at that resolution, and most of them have focused on the North Atlantic and the Gulf Stream. At that resolution, there is a significant improvement in the separation of the Gulf Stream at Cape Hatteras when compared to coarser resolution experiments [Bryan et al., 2007]. However, there are still substantial differences in the Gulf Stream's path, strength, and variability among the various high-resolution model simulations. In particular, a realistic separation in a $1 / 10^{\circ}$ basin scale simulation of the North Atlantic [Smith et al., 2000] does not guarantee that the separation be as realistic when the identical model is configured globally at the same resolution [Maltrud and McClean, 2005].

As already mentioned in the "Introduction", improvement in Gulf Stream separation in the fine mesh $\left(1 / 10^{\circ}\right.$ or higher $)$ simulations when compared to coarser resolution experiments may be due to the fact that the first baroclinic Rossby radius of deformation is resolved throughout most of the domain, thereby providing a good representation of baroclinic instability processes [Paiva et al., 1999; Smith et al., 2000; Bryan et al., 2007], or to the exceeding of some critical Reynolds number [Dengg, 1993; Tansley and Marshall, 2001], or a combination of both. This is consistent with the results of Hurlburt and Hogan [2000] who showed that the Gulf Stream separation and pathways are drastically improved when the resolution is increased from $1 / 8^{\circ}$ to $1 / 64^{\circ}$ in a series of numerical experiments with a hydrodynamic (i.e., no active thermodynamics) primitive equation model.

High resolution appears to be necessary, but it is not necessarily sufficient for a proper Gulf Stream separation. As stated by Bryan et al. [2007], substantial uncertainties remain about the robustness of the results obtained at a resolution of $1 / 10^{\circ}$ or higher. The Gulf Stream separation, indeed, turns out to be quite sensitive to a variety of other factors such as subgrid scale parameterization, subopolar gyre strength and water mass properties, DWBC strength, representation of topography, and the choice of model grid (C. Böning, R. Bourdallé-Badie, F. Bryan, M. Hecht, J. McClean, and T. Penduff, personal communication). It is not always clear why certain model configurations lead to a correct western boundary current separation while others do not. For example, Plate 2 shows the mean sea surface height field for a $1 / 12^{\circ}$ North Atlantic basin simulation using the depth-coordinate ocean model NEMO [Madec, 2006]. In this simulation, the 

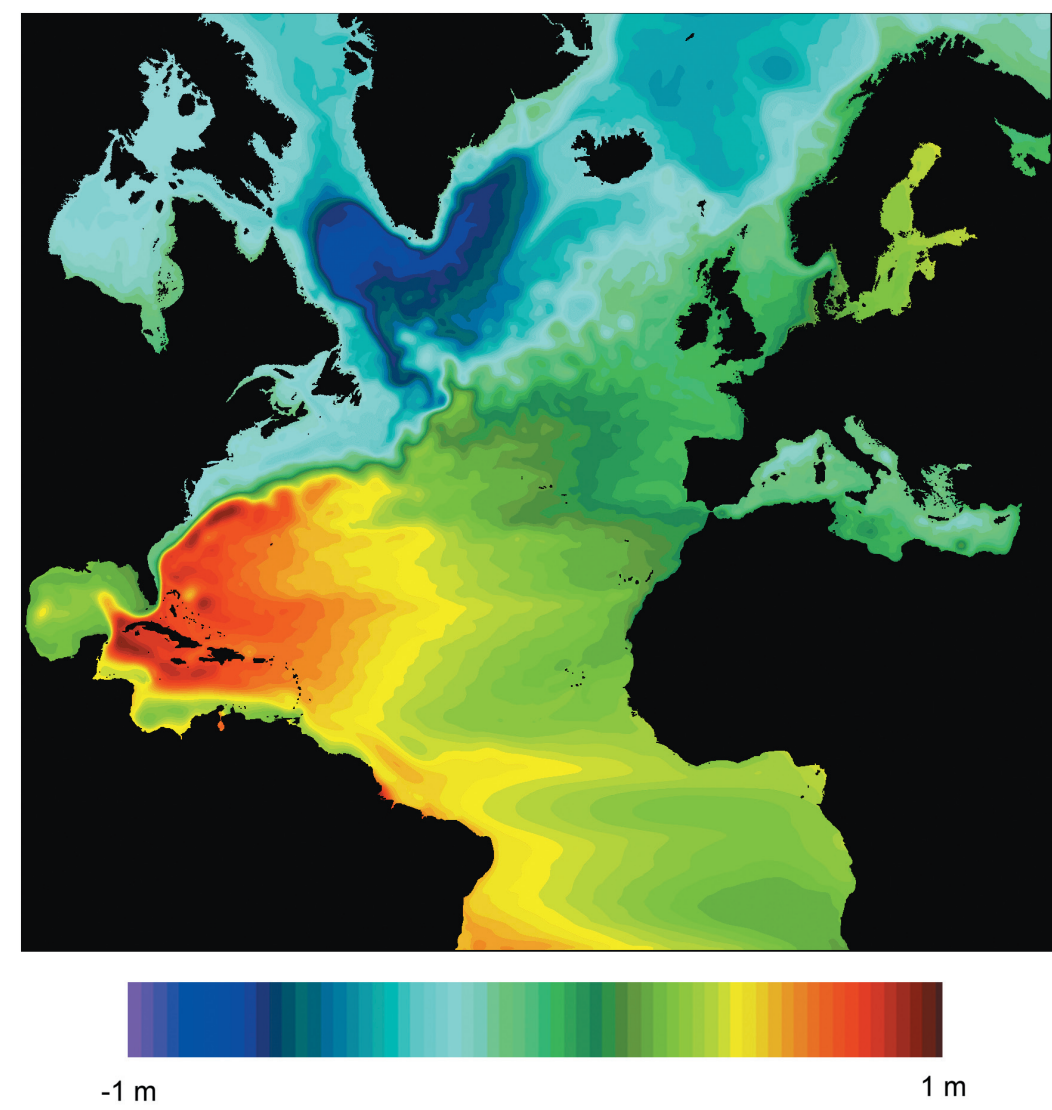

Plate 2. Three-year mean sea surface height from the $1 / 12^{\circ}$ North Atlantic depth coordinate [Nucleus for European Modelling of the Ocean (NEMO); Madec, 2006] configured over the North Atlantic between $20^{\circ} \mathrm{S}$ and $80^{\circ} \mathrm{N}$ including the Mediterranean Sea (R. Bourdallé-Badie, Y. Drillet, and O. LeGalloudec, personal communication). There are 50 levels in the vertical with an increased vertical resolution near the surface. The bathymetry is a combination of ETOPO2 bathymetry for the deep ocean and GEBCO bathymetry for the continental shelf. The north and south boundaries are buffer zones where the temperature and salinity fields are damped toward a climatological monthly mean [Levitus et al., 1998]. A free surface that filters high-frequency features is used for the surface boundary condition [Roullet and Madec, 2000]. An isopycnal Laplacian operator $\left(125 \mathrm{~m}^{2} / \mathrm{s}\right)$ is used for the lateral diffusion on the tracers, and a horizontal biharmonic operator $\left(1.25 \times 10^{-10} \mathrm{~m}^{2} / \mathrm{s}^{2}\right)$ is used for the lateral viscosity on momentum. A partial slip lateral boundary condition is prescribed along the coast. 

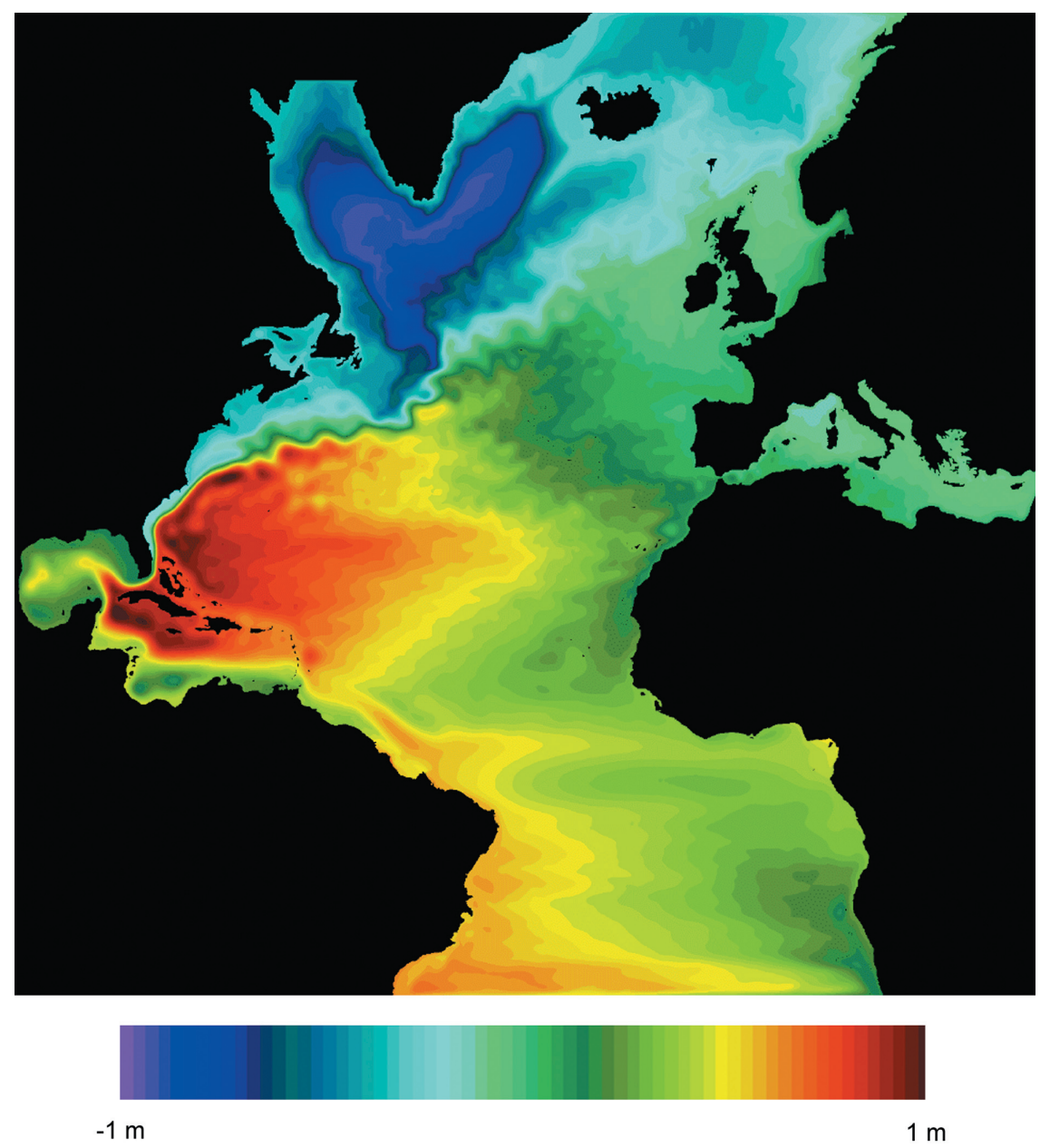

Plate 3. Three-year mean sea surface height from the $1 / 12^{\circ}$ North Atlantic isopycnic coordinate model [MICOM, Bleck et al., 1992; Bleck and Chassignet, 1994] configured over the North Atlantic between $28^{\circ} \mathrm{S}$ and $70^{\circ} \mathrm{N}$ including the Mediterranean Sea. There are 26 layers in the vertical with an increased vertical resolution near the surface. The bathymetry is a modified ETOPO5. The north and south boundaries are buffer zones where the temperature and salinity fields are damped toward a climatological monthly mean [Levitus et al., 1998]. The viscosity operator is a combination of biharmonic $\left(A_{4}=V_{\mathrm{D}} \Delta x^{3}\right.$, with $\left.V_{\mathrm{D}}=10^{-2} \mathrm{~m} / \mathrm{s}\right)$ and Laplacian $\left(A_{2}=\right.$ $\max \left[.1 \Delta x^{2} \times\right.$ deformation tensor, $V_{\mathrm{D}} \Delta x$ ], with $V_{\mathrm{D}}=5 \times 10^{-3} \mathrm{~m} / \mathrm{s}$ ) operators. For more details, the reader is referred to Chassignet and Garraffo [2001]. 
Gulf Stream separation is well represented, and the improvements over an earlier simulation [Drillet et al., 2005] are believed to be due to (a) a change in the grid orientation, (b) the use of partial cells to represent topography, (c) an energy- and enstrophy-conserving scheme, and (d) the coupling with the ice model. Indeed, Barnier et al. [2006) showed in a series of $1 / 4^{\circ}$ global experiments that the use of partial steps and of the energy- and enstrophy-conserving scheme clearly impact on the Gulf Stream separation. The impact of the energy- and enstrophy-conserving scheme was shown to be greatest at grid cells nearest to a side wall, suggesting a great sensitivity of the momentum advection to the lateral and bottom boundary conditions.

The sensitivity to parameterization choices is clearly illustrated by Bryan et al. [2007] in a series of North Atlantic basin simulations with the depth-coordinate POP ocean numerical model [Dukowicz and Smith, 1994] with a free surface and a full-cell representation of the topography. Bryan et al. [2007] investigated the sensitivity of the modeled circulation to changes in resolution from $0.4^{\circ}$ to $0.1^{\circ}$ with and without adjustment in horizontal viscosity and diffusivity. When the viscosity is adjusted along with resolution as a function of the grid spacing, the Gulf Stream separation and path improves as the resolution is increased (Figure 8). Both the $0.4^{\circ}$ and $0.2^{\circ}$ simulations exhibit the traditional stationary eddy north of Cape Hatteras, and the path of the Gulf Stream is to the north of the observed mean path. At $0.1^{\circ}$, the stationary eddy disappears, and the Gulf Stream now separates from the coast. One can also notice the development of strong northern and southern recirculation gyres.

When moving to lower viscosities in the $0.1^{\circ}$ experiments, Bryan et al. [2007] found that with decreasing viscosity, the Gulf Stream separates at a latitude south of the observed separation point at Cape Hatteras (not illustrated), the Gulf Stream path is more zonal, and the recirculation gyres strengthen. In these experiments, Bryan et al. [2007] show that the southern displacement of the separation point is linked to a strengthening of the deep outflow from the Labrador Sea and a substantial increase in the normal component of the velocity of the DWBC at the base of the Gulf Stream near $1,000 \mathrm{~m}$. This is consistent with the mechanism put forward by Thompson and Schmitz [1989], i.e., that the Gulf Stream, especially its upper core, can be displaced to the south when the DWBC strength is increased [Spall, 1996a].

The Gulf Stream separation is also sensitive to the form of the viscosity operator as illustrated by a series of $1 / 12^{\circ}$ North Atlantic simulations performed with the free surface isopycnic coordinate model MICOM [Bleck et al., 1992; Bleck and Chassignet, 1994]. Plate 3 shows the mean sea surface height field for a $1 / 12^{\circ}$ North Atlantic basin simula-
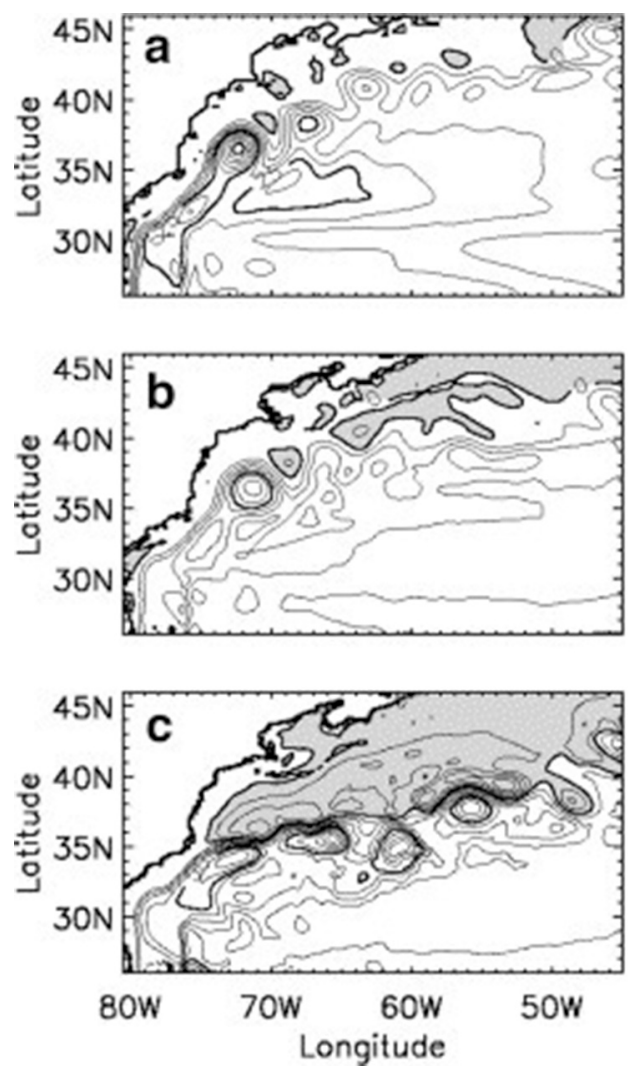

Figure 8. Three-year mean vertically integrated mass transport streamfunction over the Gulf Stream region for a series of North Atlantic basin simulations performed with the depth-coordinate POP ocean numerical model [Dukowicz and Smith, 1994] configured over the North Atlantic between $20^{\circ} \mathrm{S}$ and $73^{\circ} \mathrm{N}$ including the western Mediterranean Sea: (a) $0.4^{\circ}$, (b) $0.2^{\circ}$, and (c) $0.1^{\circ}$. The contour interval is $5 \mathrm{~Sv}$ in (a) and $10 \mathrm{~Sv}$ in (b) and (c). For more details, the reader is referred to Bryan et al. [2007].

tion using a viscosity operator that is a combination of biharmonic and Laplacian operators.

The mean sea surface height (SSH) of two biharmoniconly simulations are displayed in Figures 9 and 10 for two different magnitudes of the biharmonic viscosity coefficient. When a relatively small value of the biharmonic viscosity coefficient is used (see caption of Figure 9 for details), the western boundary current is seen to separate from the coast early at the Charleston bump before Cape Hatteras (Figure 9). A similar result was observed with the $1 / 10^{\circ}$ POP North Atlantic simulation during the spin-up phase in which both the viscosity and diffusion had to be increased by a factor of 3 to eliminate this feature [Smith et al., 2000]. An increase in the magnitude of the biharmonic viscosity operator did 


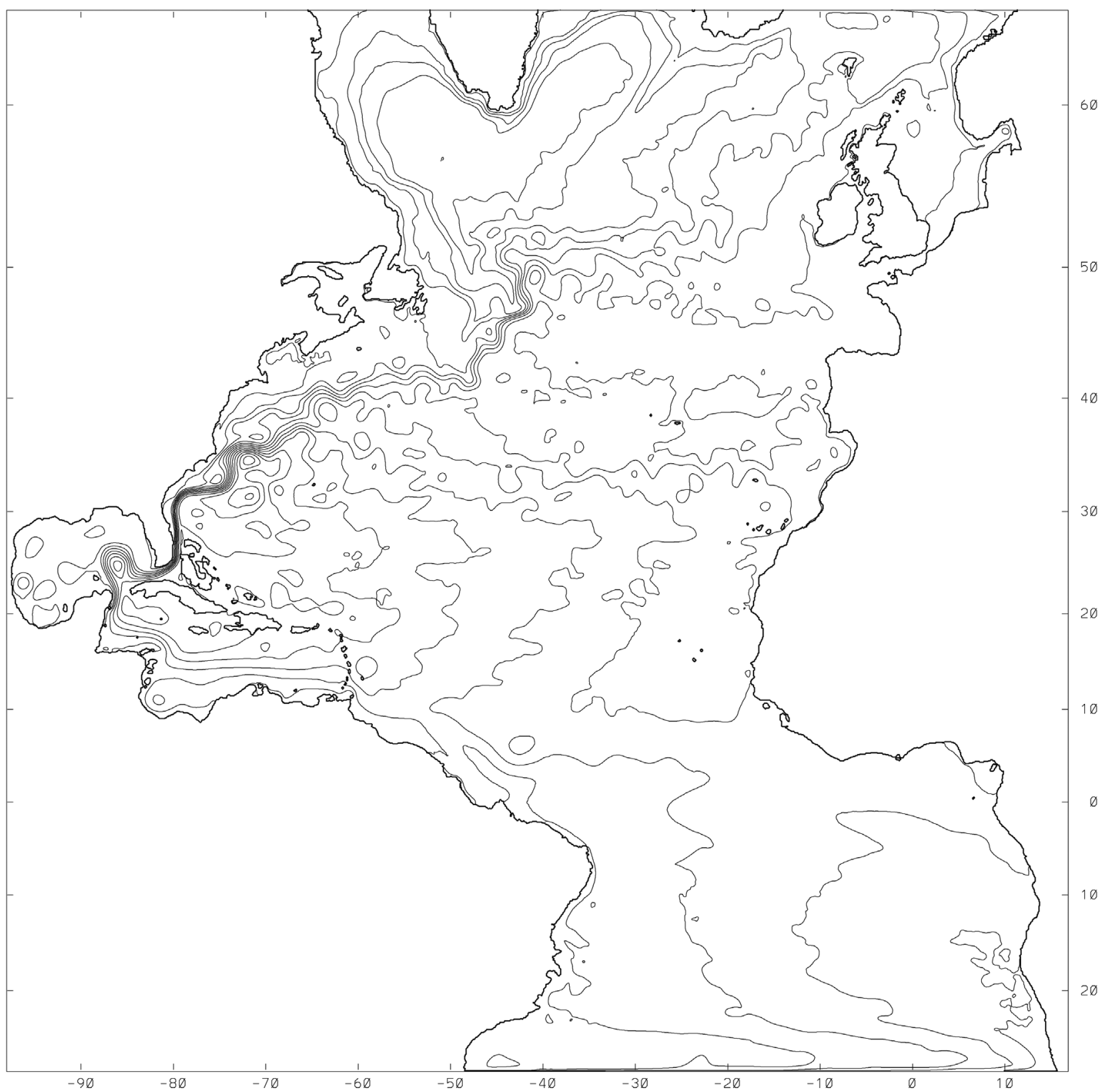

Figure 9. One-year mean sea surface height field from the $1 / 12^{\circ}$ North Atlantic isopycnic coordinate model with a biharmonic viscosity operator $\left(A_{4}=\max \left[.1 \Delta x^{4} \times\right.\right.$ deformation tensor, $\left.V_{\mathrm{D}} \Delta x^{3}\right]$, with $\left.V_{\mathrm{D}}=10^{-2} \mathrm{~m} / \mathrm{s}\right)$. For more details, the reader is referred to Chassignet and Garraffo [2001].

eliminate the early detachment seen in Figure 9, but it led to the establishment of a permanent eddy north of Cape Hatteras (Figure 10). This eddy is maintained by a series of warm core (anticyclonic) rings that propagate westward, collide with the western boundary, and is only weakly dissipated by the biharmonic viscosity operator. This behavior is reminiscent of other simulations performed with biharmonic dissipation [Smith et al., 2000]. The fact that this permanent eddy only appears in simulations that use biharmonic operators seems to indicate an incorrect representation of the eddy/mean flow and/or of the eddy/topography interactions possibly because of the scale selectiveness of the higher or- 


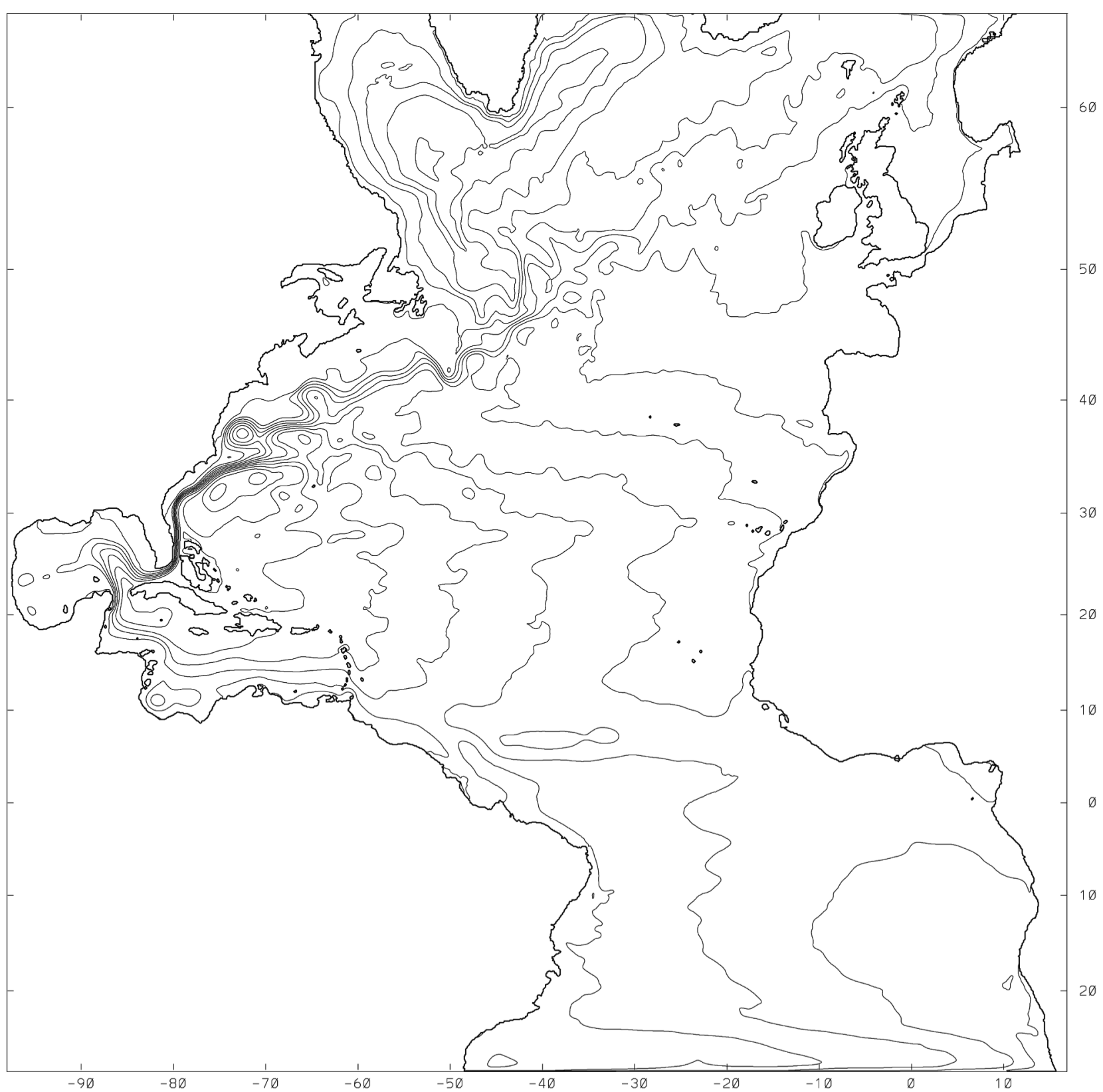

Figure 10. One-year mean sea surface height field from the $1 / 12^{\circ}$ North Atlantic isopycnic coordinate model with a biharmonic viscosity operator $\left(A_{4}=\max \left[.1 \Delta x^{4} \times\right.\right.$ deformation tensor, $\left.V_{\mathrm{D}} \Delta x^{3}\right]$, with $\left.V_{\mathrm{D}}=2 \times 10^{-2} \mathrm{~m} / \mathrm{s}\right)$. For more details, the reader is referred to Chassignet and Garraffo [2001].

der operator that allows features that are marginally resolved by the grid spacing. In all simulations, the grid spacing is such that both the inertial and the viscous boundary layers are resolved (very well for the inertial and minimally for the viscous).
The mean SSH of the simulation performed with a Laplacianonly viscosity operator is displayed in Figure 11. In that simulation, the Gulf Stream separates well from the coast, but does not penetrate further than the New England Seamounts. The magnitude of the Laplacian viscosity coefficient was the 


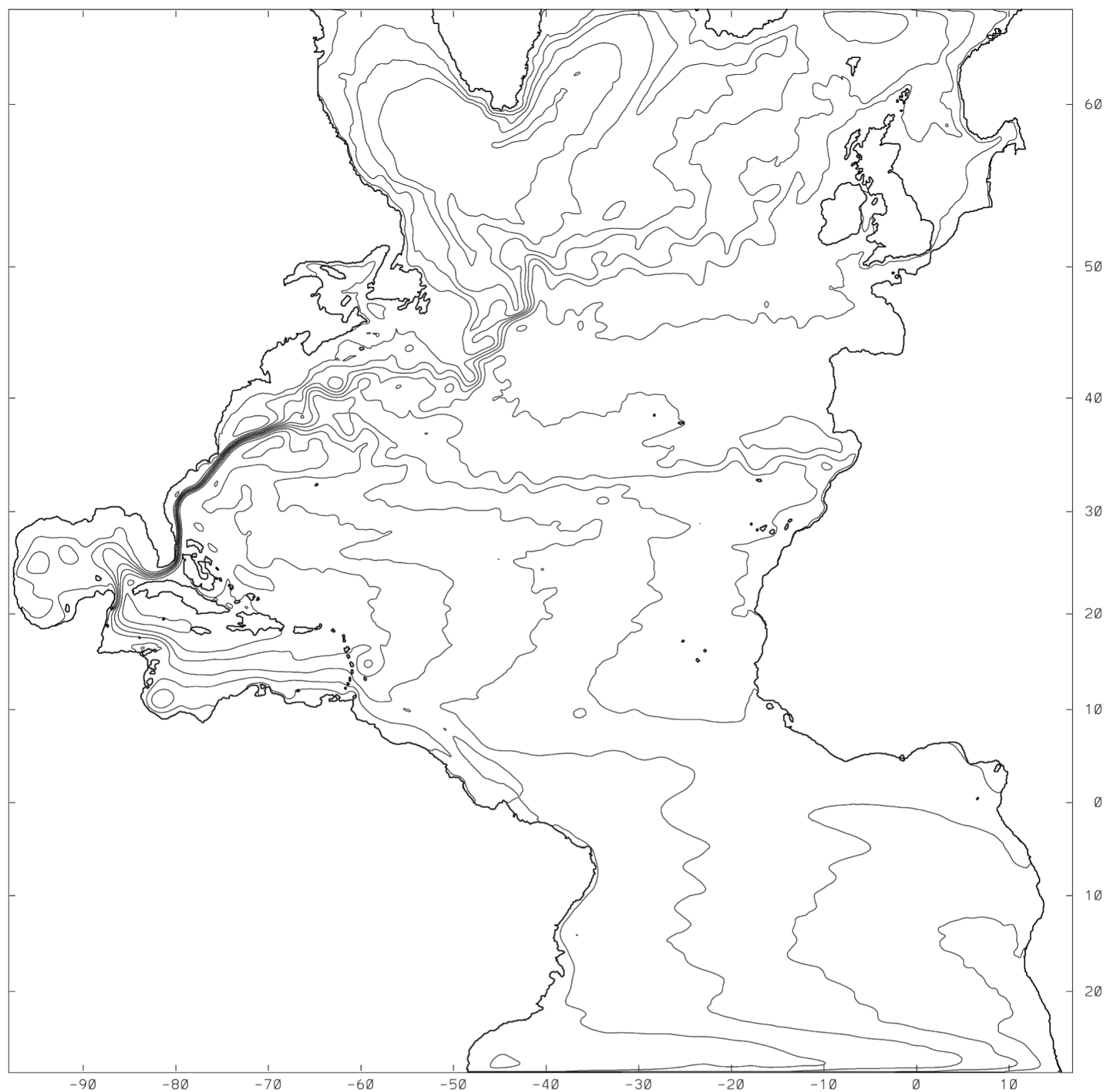

Figure 11. One-year mean sea surface height field from the $1 / 12^{\circ}$ North Atlantic isopycnic coordinate model with a Laplacian viscosity operator $\left(A_{2}=\max \left[.1 \Delta x^{2} \times\right.\right.$ deformation tensor, $\left.V_{\mathrm{D}} \Delta x\right]$, with $\left.V_{\mathrm{D}}=10^{-2} \mathrm{~m} / \mathrm{s}\right)$. For more details, the reader is referred to Chassignet and Garraffo [2001].

minimum needed for numerical stability. One can summarize the above results by stating that neither operator (Laplacian or biharmonic) is able to provide satisfactory Gulf Stream separation and penetration. With the biharmonic operator, eddies are found to retain their structure for longer periods than with a Laplacian operator, but with undesirable effects on several features of the large-scale circulation. With the Laplacian operator, the western boundary current and its separation are well represented, but with a weak penetration of the Gulf Stream. 


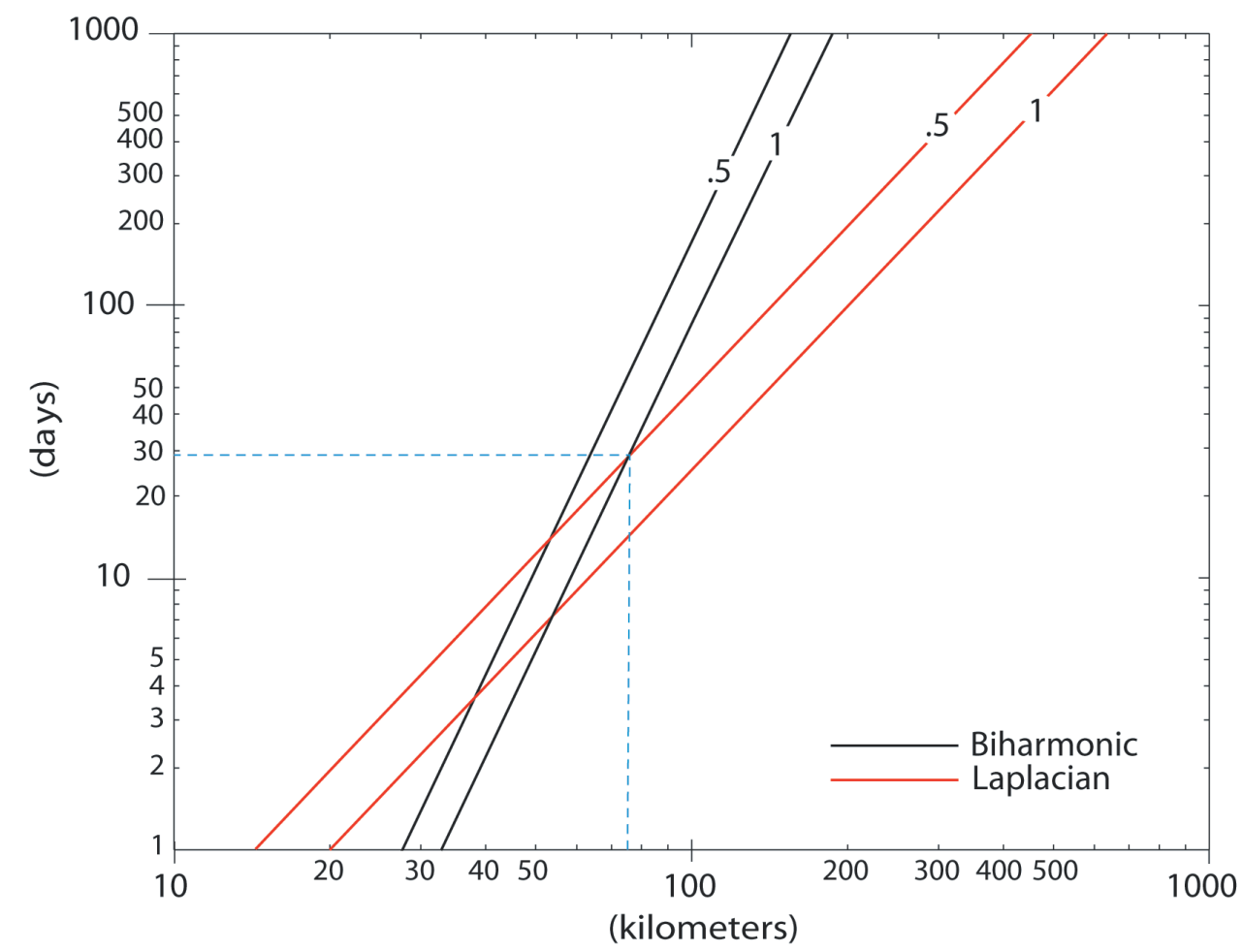

Plate 4. Laplacian and biharmonic decay timescale (in days) as a function of the wavelength $k$ (in $\mathrm{km}$ ) for values of the diffusive velocity $V_{\mathrm{D}}=.5$ and $1 \mathrm{~cm} / \mathrm{s}$, respectively.

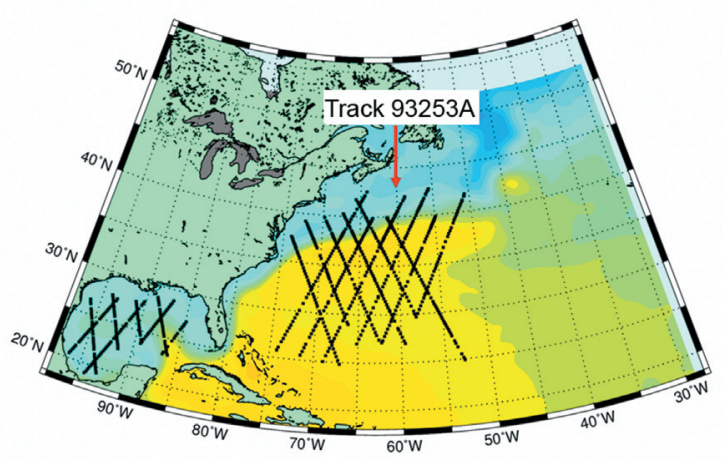

Plate 5. Location of the bathythermographic (BT) data taken during flights under the TOPEX altimeter ground tracks in September 1993. The red arrow points to track 93253A, which is used in Plate 6 to compare various mean dynamic topographies. 

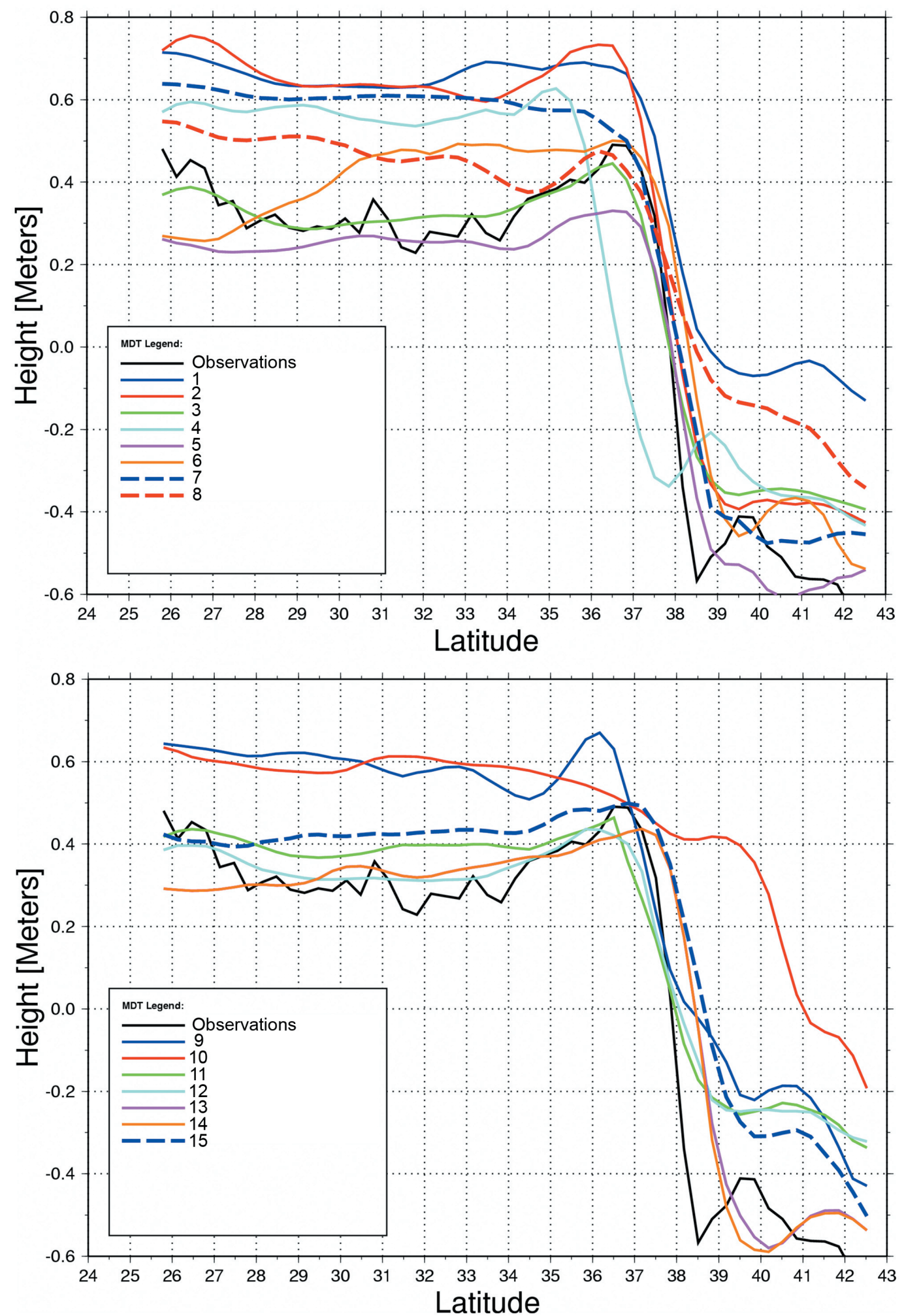

Plate 6. Mean dynamic topography (or sea surface height) in meters from four climatologies $(1,2,11$, and 12) and 11 numerical simulations $(3,4,5,6,7,8,9,10,13,14$, and 15$)$. The solid line represents the mean dynamic topography derived from the bathythermographic data and altimetry for the track identified in Plate 5. 
With a Laplacian (harmonic) dissipation operator, the evolution of a wave $c(t) e^{i k x}$ is damped exponentially with a spin-down time $\tau_{2}=A_{2}^{-1}(2 / \Delta x \sin (k \Delta x / 2))^{-2}$ In the case of a biharmonic operator, the spin-down time is $\tau_{4}=A_{4}^{-1}(2 / \Delta x \sin (k \Delta x / 2))^{-4}$. For comparison purposes, constant harmonic and biharmonic viscosity coefficients can be expressed as a function of a diffusive velocity $V_{\mathrm{D}}$ and the grid spacing $\Delta x$ as $A_{2}=V_{\mathrm{D}}$ $\Delta x$ and $A_{4}=V_{\mathrm{D}} \Delta x^{3}$, respectively. Examples of spin-down times for both operators are given in Plate 4 for the average grid spacing of the MICOM simulations $(6 \mathrm{~km})$. For the same diffusive velocity, the biharmonic operator more strongly selects the small scales to dissipate and leaves the large scales relatively untouched.

The Laplacian experiment of Figure 11, when contrasted to the biharmonic experiments of Figures 9 and 10, suggests that some damping of the larger scales is necessary for a reasonable western boundary current behavior. The best separation/penetration results are obtained when the viscosity operator is prescribed as a combination of the biharmonic and Laplacian operators (Plate 3). The main motivation for combining the two operators was to be able to retain the scale selectiveness of the biharmonic operator and to provide some damping at the larger scales [performed in this case by the Laplacian operator for $k$ greater than $80 \mathrm{~km}$ (Plate 4)]. This permits the reduction of the magnitude of the Laplacian coefficient $A_{2}$ by $50 \%$ and, at the same time, ensures numerical stability with an effective damping of the smaller scales by the biharmonic operator (Plate 4). When combined, the individual diffusive velocity $V_{\mathrm{D}}$ specified for each operator is smaller than the minimum value that is needed for numerical stability when only one of the operators is specified.

These results appear to suggest that in a realistic setting, even with such fine grid spacing, the modeled large-scale ocean circulation is strongly dependent on the choices made for the viscosity operators. Furthermore, it appears that the inverse cascade of energy from the small scales to the larger scales may not take place as anticipated and that some largescale information is needed for a proper representation of the western boundary current. In the experiments described in this paper, the latter is taking place by means of the Laplacian viscosity operator. Hyperviscosity ( $\nabla^{2 n}$ operator with $n$ $\geq 2$ ) is often used in numerical simulations of turbulent flows to extend the range of the inviscid inertial cascade. It has also been argued, however, that hypervisocsity contributes nontrivial spurious dynamics [Jiménez, 1994; Delhez and Deleersnijder, 2007].

\section{VALIDATION}

Once a numerical simulation is able to model western boundary currents that separate from the coastline at the correct latitude and with adequate interior penetration, the question remains as to whether the simulation is in agreement with observations. At the scales of interest (tens of kilometers), it is necessary to have the observed means of western boundary ocean currents and associated fronts sharply defined. Global climatologies such as the one derived from surface drifters by Niiler et al. [2003] or the one derived from altimetry and direct measurements by Rio and Hernandez [2004] can be used to validate the position of the current main axis, but they cannot be used to quantify the width and intensity of the currents because of their coarseness $\left(\sim 0.5-1^{\circ}\right.$ horizontal resolution). More specifically, the lack of an accurate geoid on the mesoscale prevents a precise computation of the ocean absolute mean dynamic topography from satellite altimetry. Several satellite missions (GRACE, GOCE) are either underway or planned to try to determine a more accurate geoid, but one will need to have measurements accurate to within a few centimeters on scales down to approximately $30 \mathrm{~km}$ so as to be useful for the above validation exercise.

An alternate approach to the validation is to determine an accurate mean dynamic topography using direct in situ measurements. An example of such an approach is to construct the mean dynamic topography along altimetric satellite ground tracks where there exist concurrent and collinear measurements of sea surface height anomalies and dynamic heights (for examples of collinear temperature and dynamic height analyses, see Carnes et al. [1990] and Blaha and Lunde [1992]). Plate 5 shows the location of the bathythermographic data taken during flights under the TOPEX altimeter ground tracks in September 1993 (courtesy of the Altimetry Data Fusion Center, Naval Oceanographic Office). To compute the mean dynamic topography, one needs to make the assumption that the dynamic topography relative to the geoid can be approximated by the dynamic height relative to a deep pressure surface that is parallel to the geoid (i.e., a level of no motion). Any error in this assumption will lead to different values of mean dynamic topography, but for the spatial scales of interest, as long as the level of no motion is deep enough, choosing a different level just adds or removes a bias. This does not affect the analysis, as we are only interested in the relative difference in mean dynamic topography across the currents (B. Lunde, personal communication).

The mean dynamic topographies displayed in Plate 6 for 4 climatologies and 11 numerical simulations show a wide range in relative difference across the Gulf Stream as well as in sharpness. For the climatologies, the Niiler et al. [2003] mean (number 2) clearly outperforms on that particular track the Rio and Hernandez [2004] mean (number 11). For the numerical simulations, the $1 / 32^{\circ}$ hydrodynamic (i.e., no thermal forcing) Navy Layered Ocean Model (NLOM) simulation (number 14) of Hurlburt and Hogan [2000] performs, 
best emphasizing again the importance of high horizontal grid spacing. Note that some of the differences between the dynamic topographies in Plate 6 may be attributed to differences in the temporal periods over which the data are compiled in the observations, climatologies, and models.

\section{CONCLUDING REMARKS}

In summary, identifying the dynamics responsible for Gulf Stream separation continues to be a challenge, and the separation mechanism in numerical models remains very sensitive to choices made in the numerical model for subgrid scale parameterizations. There is yet no single recipe that would guarantee a correct separation of all western boundary currents in a global model. While it can be firmly stated that a resolution on the order of at least $1 / 10^{\circ}$ is a necessary condition for a western boundary current to realistically separate from the coast, it is not yet clear which horizontal resolution is best for a realistic zonal penetration and variability of the separated boundary current. On one hand, a fourfold increase in resolution from $1 / 16^{\circ}$ to $1 / 64^{\circ}$ with the Laplacian operator in the hydrodynamic (i.e., no thermal forcing) NLOM [Hurlburt and Hogan, 2000] brought the sea surface height variability to observed levels without altering the pattern of the large-scale circulation. On the other hand, the experiments performed by Bryan et al. [2007] with a biharmonic operator show sea surface height variability that exceeds observations (Figure 12 of their paper). While numerical simulations at the above-noted resolutions are becoming more common, they still demand the latest in computing facilities. A fourfold increase in resolution for the thermodynamically forced models cannot be realistically implemented with the present computer resources.

Further evaluation of the impact of dissipation operators on the large-scale circulation also needs to be pursued. For example, the horizontal eddy viscosity implemented in numerical models is usually assumed to be isotropic. There is currently little theoretical or observational evidence to support that assumption, and substantial anisotropy can be generated by the direction of the mean flow in a strong jet [Smith and McWilliams, 2003], although more recent theoretical [Theiss, 2004] and observational [Eden, 2007] analysis suggests that anisotropy can be generated by the $\beta$ effect. An anisotropic formulation of the viscosity that incorporates the feature of larger along-stream than cross-stream diffusion for zonal jets was first introduced into a coarse-resolution OGCM by Large et al. [2001] to improve the simulation of the equatorial currents in the Pacific Ocean. When applied globally, Doney et al. [2003] found some improvements in the separation points of western boundary currents, although their results were sensitive to the specific choice of viscous parameters. Smith and Gent [2004], using both anisotropic viscosity and an anisotropic Gent and McWilliams [1990] scheme, also found improvements in the separation and path of the Gulf Stream at $0.1^{\circ}$ and $0.2^{\circ}$ resolutions. The anisotropic Gent and McWilliams [1990] scheme led to the greatest overall model improvements especially in the meridional overturning circulation, supporting the argument of Roberts and Marshall [1998] for the use of adiabatic tracer diffusion even at eddy-resolving scales.

Finally, we would like to emphasize that a judicious use of data assimilation should increase our physical understanding of western boundary current separation in numerical models. Data assimilation can be used to estimate model parameters by taking into account both the information provided by the model dynamics and by the observations [see Bennett, [1992]; Wunsch [1996]; Evensen et al. [1998]; and Bennett [2002] for a review], but there are still many challenges remaining before parameter estimation can be directly applied to eddyresolving OGCMs. Because of its complexity and nonlinearity, parameter estimation is mostly used in the context of simple dynamical models or idealized configurations. A nice example is the work in progress of A. Wirth and J. Verron in which the outputs of a numerical model that explicitly resolves the entrainment process in gravity currents are used to estimate which frictional parameterization is most adequate in representing the turbulent fluxes that are not resolved in coarser horizontal resolution numerical models.

Acknowledgments. We express our appreciation to Bruce Lunde of the Naval Oceanographic Office and Ole Martin Smedstad of Planning Systems, Inc. for performing the mean dynamic topography analysis presented in Section 5 and for providing Plates 5 and 6 . We also would like to thank an anonymous reviewer, L. Bunge, M. Hecht, H. Hurlburt, J. O'Brien, and J. Verron for insightful comments.

\section{REFERENCES}

Adcroft, A., and D. Marshall (1998), How slippery are piecewiseconstant coastlines in numerical ocean models?, Tellus, 50A, 95-108.

Agra, C., and D. Nof (1993), Collision and separation of boundary currents. Deep Sea Res., 40, 2259-2282.

Anderson, D. L. T., and D. W. Moore (1979), Cross-equatorial inertial jets with special relevance to very remote forcing of the Somali Current. Deep Sea Res., 26, 1-22.

Baines, P. G., and R. L. Hughes (1996), Western boundary current separation: Inferences from a laboratory model. J. Phys. Oceanogr., 26, 2576-2588.

Barnier, B., G. Madec, T. Penduff, J.-M. Molines, A.-M. Treguier, J. Le Sommer, A. Beckmann, A. Biastoch, C. Böning, J. Dengg, C. Derval, E. Durand, S. Gulev, E. Remy, C. Talandier, S. Theetten, M. Maltrud, J. McClean, and B. De Cuevas (2006), Impact 
of partial steps and momentum advection schemes in a global ocean circulation model at eddy-permitting resolution. Ocean Dyn., 56, 543-567.

Bennett, A. F. (1992), Inverse Methods in Physical Oceanography, 346 pp., Cambridge University Press, Cambridge.

Bennett, A. F. (2002), Inverse Modeling of the Ocean and Atmosphere, 234 pp., Cambridge University Press, Cambridge.

Blaha, J., and B. Lunde (1992), Calibrating altimetry to geopotential anomaly and isotherm depths in the Western North Atlantic, J. Geophys. Res., 97, 7465-7477.

Blandford, R. R. (1971), Boundary conditions in homogeneous ocean models. Deep Sea Res., 18, 739-751.

Bleck, R. (2002), An oceanic general circulation model framed in hybrid isopycnic-Cartesian coordinates, Ocean Model, 4, 55-88.

Bleck, R., and E. P. Chassignet (1994), Simulating the oceanic circulation with isopycnic coordinate models. The Oceans: Physiochemical Dynamics and Resources. The Pennsylvania Academy of Science, pp. 17-39.

Bleck, R., C. Rooth, D. Hu, and L. T. Smith (1992), Salinity-driven transients in a wind- and thermohaline-forced isopycnic coordinate model of the North Atlantic. J. Phys. Oceanogr., 22, 1486-1505.

Bryan, F. O., M. W. Hecht, and R. D. Smith (2007), Resolution convergence and sensitivity studies with North Atlantic circulation models. Part I: The western boundary current system. Ocean Modelling, 16, 141-159.

Carnes, M. R., J. L. Mitchell, and P. W. de Witt (1990), Synthetic temperature profiles derived from GEOSAT altimetry: comparison with air-dropped expendable bathy thermograph profiles. J. Geophys. Res., 95, 17,979-17,992.

Cessi, P. (1990), Geometrical control of the inertial recirculation. $J$. Phys. Oceanogr, 20, 1867-1875.

Cessi, P. (1991) Laminar separation of colliding western boundary currents. J. Mar. Res., 49, 697-717.

Cessi P., G. Ierley, and W. Young (1987), A model of intertial recirculation driven by potential vorticity anomalies. J. Phys. Oceanogr., 17, 1640-1652.

Cessi, P., R. V. Condie, and W. R. Young (1990), Dissipative dynamics of western boundary currents. J. Mar. Res., 48, 677-700.

Chassignet, E. P. (1995), Vorticity dissipation by western boundary currents in the presence of outcropping layers. J. Phys. Oceanogr., 25, 242-255.

Chassignet, E. P., and R. Bleck (1993), The influence of layer outcropping on the separation of boundary currents. Part I: The wind-driven experiments, J. Phys. Oceanogr., 23, 1485-1507.

Chassignet, E. P., and Z. D. Garraffo (2001), Viscosity parameterization and the Gulf Stream separation, in From Stirring to Mixing in a Stratified Ocean, Proceedings 'Aha Huliko'a Hawaiian Winter Workshop January 15-19, 2001, edited by P. Muller and D. Henderson, pp. 37-41, University of Hawaii.

Chassignet, E. P., and P. R. Gent (1991), The influence of boundary conditions on mid-latitude jet separation in ocean numerical models. J. Phys. Oceanogr., 21, 1290-1299.

Chassignet, E. P., and C. G. H. Rooth (1995), The influence of layer outcropping on the separation of boundary currents. Part II: The wind- and buoyancy-driven experiments. J. Phys. Oceanogr., 25, 2404-2422.
Cherniawsky, J., and G. Holloway (1991), An upper ocean general circulation model for the North Pacific: Preliminary experiments. Atmos. Ocean, 29, 737-784.

Delhez, E. J. M., and E. Deleersnijder (2007), Overshootings and spurious oscillations caused by biharmonic mixing. Ocean Modelling, 17, 183-198.

Dengg, J. (1993), The problem of Gulf Stream separation: A barotropic approach. J. Phys. Oceanogr., 23, 2182-2200.

Dengg, J., A. Beckmann, and R. Gerdes (1996), The Gulf Stream separation problem, in The Warmwatersphere of the North Atlantic, pp. 253-289, edited by W. Kraus, Gebruder Borntrager, Berlin.

Doney, S. C., S. Yeager, G. Danabasoglu, W. Large, and J. C. McWilliams (2003), Modeling global oceanic interannual variability (1958-1997): Simulation design and model-data evaluation. NCAR Technical Note, NCAR/TN-452+STR, 48 pp.

Drillet, Y., R. Bourdallé-Badie, L. Siefridt, and C. Le Provost (2005), Meddies in the Mercator North Atlantic and Mediterranean Sea eddy-resolving model. J. Geophys. Res., 110, C03016, doi:10.1029/2003JC002170.

Dukowicz, J. K., and R. D. Smith (1994), Implicit free-surface method for the Bryan-Cox-Semtner ocean model. J. Geophys. Res., 99, 7991-8014.

Dupont, F., D. N. Straub, and C. A. Lin (2003), Influence of a steplike coastline on the basin scale vorticity budget of mid-latitude gyre models. Tellus, 55A, 255-272.

Eby, M., and G. Holloway (1994), Sensitivity of a large scale ocean model to a parameterization of topographic stress. J. Phys. Oceanogr. 24, 2577-2588.

Eden, C. (2007), Eddy length scales in the North Atlantic Ocean. J. Geophys. Res., 112, C06004, doi:10.1029/2006JC003901.

Evensen G., D. Dee, and J. Schröter (1998), Parameter estimation in dynamical models, in Ocean Modeling and Parameterization, NATO Science Series, pp. 373-398, edited by E. P. Chassignet, and J. Verron, Kluwer, New York.

Ezer, T., and G. L. Mellor (1992), A numerical study of the variability and the separation of the Gulf Stream induced by surface atmospheric forcing and lateral boundary flows. J. Phys. Oceanogr., 22, 660-682.

Gangopadhyay, A., P. Cornillon, and D. R. Watts (1992), A test of the Parsons-Veronis hypothesis related to the separation of the Gulf Stream from the coast. J. Phys. Oceanogr., 22, 1286-1301.

Gent, P. R., and J. C. McWilliams (1990), Isopycnal mixing in ocean circulation models. J. Phys. Oceanogr., 20, 150-155.

Greenspan, H. P. (1963), A note concerning topography and inertial currents. J. Mar. Res., 21, 147-154.

Haidvogel, D., J. McWilliams, and P. Gent (1992), Boundary current separation in a quasigeostrophic, eddy-resolving ocean circulation model. J. Phys. Oceanogr., 22, 882-902.

Harrison, D. E., and W. R. Holland (1981), Regional eddy vorticity transport and the equilibrium vorticity budgets of a numerical model ocean circulation. J. Phys. Oceanogr., 11, 190-208.

Holland, W. R. (1967), On the wind-driven circulation in an ocean with bottom topography. Tellus, 19, 582-600.

Holland, W. R. (1973), Baroclinic and topographic influences on the transport in western boundary currents. Geophys. Fluid Dyn., $4,187-210$. 
Holloway, G. (1992), Representing topographic stress for largescale ocean models. J. Phys. Oceanogr., 22, 1033-1046.

Huang, R. X. (1987), A three-layer model for wind-driven circulation in a subtropical-subpolar basin. Part I. Model formulation and the subcritical state. J. Phys. Oceanogr., 17, 664-678.

Huang, R. X., and G. R. Flierl (1987), Two-layer models for the thermocline and current structure in the subtropical/subpolar gyres. J. Phys. Oceanogr., 17, 872-884.

Hurlburt, H. E., and P. J. Hogan (2000), Impact of $1 / 8^{\circ}$ to $1 / 64^{\circ}$ resolution on Gulf Stream model-data comparisons in basinscale subtropical Atlantic ocean models. Dyn. Atmos. Oceans, $32,283-329$.

Hulburt, H. E., and P. J. Hogan (2008), The Gulf Stream pathway and the impacts of the eddy-driven abyssal circulation and the deep western boundary current, Dyn. Atmos. Oceans, (submitted).

Hurlburt, H. E., E. J. Metzger, P. J. Hogan, C. E. Tillburg, J. F. Shriver, and O. M. Smedstad (2008), Pathways of upper ocean currents and fronts: Steering by topographically-constrained abyssal circulation and the role of flow instabilities, applicability of a two-layer theory to low vs. high vertical resolution models. Dyn. Atmos. Oceans, (submitted).

Ierley, G. R. (1987), On the onset of recirculation in barotropic general circulation models. J. Phys. Oceanogr., 17, 2366-2374.

Ierley, G. R., and O. G. Ruehr (1986), Analytic and numerical solutions of a nonlinear boundary layer problem. Stud. Appl. Math., $75,1-36$

Ierley, G., and W. Young (1988), Inertial recirculation in a $\beta$-plane corner. J. Phys. Oceanogr., 18, 683-689.

Isemer, H. J., and L. Hasse (1987), The Bunker Climate Atlas of the North Atlantic Ocean. Vol. 2, Air-Sea Interactions, 252 pp., Springer, Berlin.

Jiang, S., Jin, F.-F., and Ghil, M. (1995), Multiple equilibria and aperiodic solutions in a wind-driven double-gyre, shallow-water model, J. Phys. Oceanogr., 25, 764-786.

Jiménez, J. (1994), Hyperviscous vortices. J. Fluid Mech., 279, 169-176.

Kamenkovich, V. M. (1966), A contribution to the theory of the inertial-viscous boundary layer in a two-dimensional model of ocean currents. Isvestiya, 97, 781-792.

Kamenkovich, V. M., and G. M. Reznik (1972), A contribution to the theory of stationary wind-driven currents in a two-layer liquid. (English transl.), Izv. Acad. Sci. USSR Atmos. Oceanic Phys., 8, 238-245.

Katsman, C. A., S. S. Drijfhout, and H. A. Dijkstra (2001), The interaction of a deep western boundary current and the winddriven gyres as a cause for low-frequency variability. J. Phys. Oceanogr., 31, 2321-2339.

Kiehl, J. T., and P. R. Gent (2004), The community climate system model, version two. J. Clim., 17, 3666-3682.

Kiss, A., E. (2002), Potential vorticity "crises", adverse pressure gradients and western boundary current separation. J. Mar. Res., 60, 779-803.

Large, W.G., G. Danabasoglu, J. C. McWilliams, P. R. Gent, and F. O. Bryan (2001), Equatorial circulation of a global ocean climate model with anisotropic horizontal viscosity. J. Phys. Oceanogr., $31,518-536$.
Madec G. (2006), NEMO Reference Manual, Ocean Dynamic Component: NEMO-OPA, Institut Pierre Simon Laplace (IPSL), 27, ISSN 1288-1619.

Maltrud, M. E., and J. L. McClean (2005), An eddy resolving global $1 / 10^{\circ}$ ocean simulation. Ocean Modelling, 8, 31-54.

Marshall, D. P., and C. E. Tansley (2001), An implicit formula for boundary current separation. J. Phys. Oceanogr., 31, 1633-1638.

Mertz, G., and D. G. Wright (1992), Interpretations of the JEBAR term. J. Phys. Oceanogr., 22, 301-305.

Moore, D.W., and P. Niiler (1974), A two-layer model for the separation of inertial boundary currents. J. Mar. Res., 32, 457-484.

Moro, B., 1988: On the nonlinear Munk model. Part I: Steady flows. Dyn. Atmos. Oceans, 12, 259-287.

Munday, D. R., and D. P. Marshall (2005), On the separation of a barotropic western boundary current from a cape. J. Phys. Oceanogr., 35, 1726-1743.

Munk, W. H. (1950), On the wind-driven circulation. J. Meteor., 7, 79-93.

Myers, P. G., A. F Fanning, and A. J. Weaver (1996), JEBAR, bottom pressure torque and Gulf Stream separation. J. Phys. Oceanogr., 26, 671-683.

Nauw, J. J., H. A. Dijkstra, and E. P. Chassignet (2004), Frictionallyinduced asymmetries in wind-driven flows. J. Phys. Oceanogr., 34, 2057-2072.

Niiler, P. P., N. A. Maximenko, and J. C. McWilliams (2003), Dynamically balanced absolute sea level of the global ocean derived from near-surface velocity observations, Geophys. Res. Lett., 30(22), 2164, doi:10.1029/2003GL018628.

Nurser, A.J.G. and R.G. Williams (1990), Cooling the Parsons' model of the separated Gulf Stream. J. Phys. Oceanogr., 20, 1974-1979.

Ou, H. W., and W. P. M. de Ruijter (1986), Separation of an inertial boundary current from a curved coastline. J. Phys. Oceanogr., 16, 280-289.

Özgökmen, T. M., E. P. Chassignet, and A. M. Paiva (1997), Impact of wind forcing, bottom topography, and inertia on midlatitude jet separation in a quasigeostrophic model. J. Phys. Oceanogr., 27, 2460-2476.

Paiva, A. M., J. T. Hargrove, E. P. Chassignet, and R. Bleck (1999), Turbulent behavior of a fine-mesh (1/12 degree) numerical simulation of the North Atlantic. J. Mar. Syst., 21, 307-320.

Parsons, A. T. (1969), A two-layer model of Gulf Stream separation. J. Fluid Mech., 39, 511-528.

Pedlosky, J. (1965), A necessary condition for the existence of an inertial boundary layer in a baroclinic ocean. J. Mar. Res., 23, 69-72.

Pedlosky, J. (1987), On Parsons' model of the ocean circulation. $J$. Phys. Oceanogr., 17, 1571-1582.

Pedlosky, J. (1996), Ocean Circulation Theory, 453 pp., Springer, Berlin.

Pickart R. S., and W. M. Smethie (1993), How does the deep western boundary current cross the Gulf Stream? J. Phys. Oceanogr., 23, 2602-2616.

Piggott, M. D., C. C. Pain, G. J. Gorman, D. P. Marshall, and P. D. Killworth (2008), Unstructured, adaptive meshes for ocean modelling, this volume. 
Rio, M.-H., and F. Hernandez (2004), A mean dynamic topography computed over the world ocean from altimetry, in situ measurements, and a geoid model. J. Geophys. Res., 109, C12032 doi:10.1029/2003JC002226.

Roberts, M., and D. Marshall (1998), Do we require adiabatic dissipation schemes in eddy-resolving ocean models? J. Phys. Oceanogr., 28, 2050-2063.

Salmon, R. (1992), A two-layer Gulf Stream over a continental slope. J. Mar. Res., 50, 341-365.

Salmon, R. (1994), Generalized two-layer models of ocean circulation. J. Mar. Res., 52, 865-908.

Sarkisyan, A. S., and V. F. Ivanov (1971), Joint effect of baroclinicity and bottom relief as an important factor in the dynamics of sea currents. Izv. Akad. Nauk SSSR, Fiz. Atmos. Okeana, 7, 173 (Engl. transl., p. 116).

Smith, N. R., and C. B. Fandry (1976), A simple model of Gulf Stream separation. J. Phys. Oceanogr., 6, 22-28.

Smith, R. D., and P. R. Gent (2004), Anisotropic Gent-McWilliams parameterization for ocean models. J. Phys. Oceanogr., 34, 2541-2564.

Smith, R. D., and J. C. McWilliams (2003) Anisotropic horizontal viscosity for ocean models. Ocean Modelling, 5, 129-156.

Smith, R. D., M. E. Maltrud, F. O. Bryan, and M. W. Hecht (2000), Numerical simulation of the North Atlantic Ocean at $1 / 10^{\circ} . J$. Phys. Oceanogr., 30, 1532-1561.

Spall, M. A. (1996a), Dynamics of the Gulf Stream/deep western boundary current crossover. Part I: Entrainment and recirculation. J. Phys. Oceanogr., 26, 2152-2168.

Spall, M. A. (1996b), Dynamics of the Gulf Stream/deep western boundary current crossover. Part II: Low frequency internal oscillations. J. Phys. Oceanogr., 26, 2169-2182.

Spitz, Y. H., and D. Nof (1991), Separation of boundary currents due to bottom topography. Deep Sea Res., 38, 1-20.

Stern, M. E. (1998), Separation of a density current from the bottom of a continental shelf. J. Phys. Oceanogr., 28, 2040-2049.
Stern, M. E., and J. A. Whitehead (1990), Separation of a boundary jet in a rotating fluid. J. Fluid Mech., 217, 41-69.

Stommel, H. (1948), The westward intensification of wind-driven ocean currents. Trans. Am. Geophys. Union, 29, 202-206.

Tansley, C. E., and D. P. Marshall (2000), On the influence of bottom topography and the deep western boundary current on Gulf Stream separation. J. Mar. Res., 58, 297-325.

Tansley, C. E., and D. P. Marshall (2001), Flow past a cylinder on a $\beta$-plane, with application to Gulf Stream separation and the Antarctic cirumpolar current. J. Phys. Oceanogr., 31, 3274-3288.

Theiss, J. (2004), Equatorward energy cascade, critical latitude, and the predominance of cyclonic vortices in geostrophic turbulence. J. Phys. Oceanogr., 34, 1663-1678.

Thompson, L. (1995), The effect of continental rises on the winddriven ocean circulation. J. Phys. Oceanogr., 15, 1296-1316.

Thompson, J. D., and W. J. Schmitz, Jr. (1989), A limited area model of the Gulf Stream: Design, initial experiments, and model-data intercomparison. J. Phys. Oceanogr., 19, 791-814.

Veronis, G. (1973), Model of world ocean circulation: I. Winddriven, two-layer. J. Mar. Res., 31, 228-288.

Veronis, G. (1976), Model of world ocean circulation: II. Thermally driven, two-layer. J. Mar. Res., 34, 199-216.

Veronis, G. (1978), Model of world ocean circulation: III. Thermally and wind driven. J. Mar. Res., 36, 1-44.

Verron, J., and E. Blayo (1996), The no-slip condition and separation of western boundary currents. J. Phys. Oceanogr., 26, 1938-1951.

Verron, J., and C. Le Provost (1991), Response of eddy-resolved general circulation numerical models to asymmetrical wind forcing. Dyn. Atmos. Oceans, 15, 505-533.

Warren, B. A. (1963), Topographic influences on the path of the Gulf Stream. Tellus, 15, 167-183.

Wunsch, C. (1996), The Ocean Circulation Inverse Problem, 442 pp., Cambridge University Press, Cambridge. 